\title{
A Safety Program in a Tertiary Care Center Emergency Department: An Evidence-Based Project to Increase Safety Event Reporting and Improve Frontline Staff Perceptions of Hospital Management's Response to Safety Events
}

Elizabeth Anne McMaster

University of St. Augustine for Health Sciences, e.mcmaster@usa.edu

DOI: https://doi.org/10.46409/sr.FKMN3659

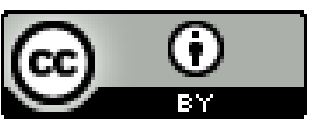

This work is licensed under a Creative Commons Attribution 4.0 License.

Follow this and additional works at: https://soar.usa.edu/scholprojects

Part of the Nursing Commons, Patient Safety Commons, and the Quality Improvement Commons

\section{Recommended Citation}

McMaster, E. A. (2021). A Safety Program in a Tertiary Care Center Emergency Department: An EvidenceBased Project to Increase Safety Event Reporting and Improve Frontline Staff Perceptions of Hospital Management's Response to Safety Events. [Doctoral project, University of St Augustine for Health Sciences].SOAR @ USA: Student Scholarly Projects Collection. https://doi.org/10.46409/sr.FKMN3659

This Scholarly Project is brought to you for free and open access by the Student Research at SOAR @ USA. It has been accepted for inclusion in Student Scholarly Projects by an authorized administrator of SOAR @ USA. For more information, please contact soar@usa.edu, erobinson@usa.edu. 


\section{A Safety Program in a Tertiary Care Center Emergency}

Department: An Evidence-Based Project to Increase Safety

Event Reporting and Improve Frontline Staff Perceptions of

Hospital Management's Response to Safety Events

Elizabeth McMaster, BSN, RN

School of Nursing, University of St. Augustine for Health Sciences

This Manuscript Partially Fulfills the Requirements for the Doctor of Nursing Practice Program and is Approved by:

Jennifer Mensik Kennedy, PhD, RN, NEA-BC, FAAN

Deborah Saber, PhD, RN, CCRN-K

Approved: Aril 7th, 2021 


\begin{abstract}
Practice Problem: The lack of a non-punitive safety culture with a healthcare organization is associated with decreased safety event reporting, reimbursement rates, and staff satisfaction.

PICOT: The PICOT question that guided this project was: In emergency department frontline staff, does hospital management involvement in a safety event program, contrasted with no safety event program, improve frontline staff's reporting of safety events and perceptions of hospital management's response to safety events management involvement over four weeks?

Evidence: Three overlapping themes that guided this project included: improving organizational culture, open communication, and leadership support in promoting patient safety.

Intervention: A safety event program, Safety STOP, was utilized as an evidence-based intervention to improve employee reporting of safety events and perceptions.
\end{abstract}

Outcome: The intervention did not significantly impact frontline staff perceptions of hospital management's response to safety events; however, the proportion of safety events reported during the implementation phase was significantly higher than the proportion of safety events reported before the intervention.

Conclusion: Safety STOP had a significant impact on the organization. After initial implementation, Safety STOP was implemented hospital-wide, reduced the total number of sentinel events required to be reported to the state, and reduced the total time from safety event to root cause analysis.

Keywords: safety, safety event, healthcare, safety culture, staff perceptions, leadership 


\section{A Safety Program in a Tertiary Care Center Emergency Department: An Evidence-Based Project to Increase Safety Event Reporting and Improve Frontline Staff Perceptions of Hospital Management's Response to Safety Events}

Despite best efforts, humans, technology, and processes still have gaps that allow safety errors to occur, causing up to 98,000 patient deaths nationally per year (Meyer, 2019; Moeller et al., 2019). Safety errors, incidents, and harm are estimated to cost patients, families, and healthcare organizations between 17 and 29 billion dollars annually in the United States (U.S.) alone (Meyer, 2019). Focusing on a culture of safety within health care systems and empowering staff to speak up and report both potential and actual safety events is an ethical and economic responsibility of healthcare caregivers (Novak, 2019). Every safety incident or error prevented will save an organization an average of 13,000 dollars (Novak, 2019).

The purpose of this Doctor of Nursing Practice (DNP) project was to show an increase in the reporting rates of safety events and improve the frontline staff's perceptions of hospital management's response to safety events in the emergency department (ED). This DNP project aimed to identify a change process that would promote timely responses, transparency, and staff accolades of response to safety events.

\section{Significance of the Practice Problem}

In 2019, the organization where the DNP project was completed ranked second to last in their organizational healthcare system's Culture of Safety Survey, which compared nine healthcare organizations within the network (NLH, 2019a). The survey results highlighted the need to build a non-punitive safety culture within the organization that supported bringing forward safety concerns (NLH, 2019a; Polonsky, 2019). The penalties associated with the Affordable Care Act's effort to encourage better care cost the organization over two million 
dollars of Medicare reimbursements in the 2020 fiscal year (E. Perry, personal communication, May 10, 2020; Kaiser Family Foundation, 2020). Among 17 non-exempt hospitals in the state, this organization is one of four hospitals receiving reduced payments due to preventable complications (Kaiser Family Foundation, 2020). Additionally, it is one of 786 hospitals in the U.S. in the 2020 fiscal year, which received lower reimbursement rates from the Centers for Medicare and Medicaid Services (CMS) due to higher rates of infection and patient injuries compared to other national hospitals (Kaiser Family Foundation, 2020).

The data collected in an annual staff satisfaction survey revealed that $27 \%$ of staff felt reporting a safety event would result in punitive repercussions, and more than $25 \%$ of staff reported they would not freely speak up if they saw something that may affect patient care (NLH, 2019a). The Agency for Healthcare Research and Quality (AHRQ) survey highlighted areas of opportunity such as management and supervisor support for patient safety, learning from errors, non-punitive response to errors, communication openness, frequency of events reported, teamwork across units, and perceptions of safety (NLH, 2019a). In May 2020, the organization documented over 96 sentinel events and, due to the survey results, leadership recognized they were in jeopardy of missing opportunities to prevent safety events from reoccurring.

Leadership recognized an intervention was necessary to improve the current culture of safety, the quality of care patients receive and reduce the financial burden to the organization due to fines, penalties, and litigation (E. Perry, personal communication, May 10, 2020; NLH, 2019a).

\section{PICOT Question}

In emergency department frontline staff, does hospital management involvement of a safety event program, contrasted with no safety event program, increase employee reporting and 
improve frontline staff's perceptions of management's response to safety events over a four-week period? The project took place in the emergency department of a tertiary healthcare center and included the population of frontline ED healthcare workers, such as nurses, physicians, nursing assistants, physician assistants, and nurse practitioners. Ancillary staff were not included as participants in this project. The intervention included implementing a safety event program using evidence-based practices to demonstrate a commitment to improving hospital management's response to safety events. The practices fostered a non-punitive culture and focused on improving organizational systems rather than individuals. The intervention aimed to increase the reporting of safety events and to build a trusting relationship between frontline healthcare staff and hospital management. The comparison intervention was derived from the total number of safety events reported in RL Solutions, the online reporting system, during the same period of the previous year and was used as the baseline data. The data collected to measure the perceptions of hospital management's response to safety events were collected using a pre and post-implementation survey.

This DNP project's intended outcomes were to improve hospital management's response and guidance of safety events, improve frontline staff perceptions of management's timeliness to safety events, and increase the total number of safety events reported. This DNP project was implemented over a four-week period from October 5, 2020, to October 30, 2020. The University of St. Augustine for Health Sciences (USAHS) Review Board and the organization's Institutional Review Board (IRB) reviewed and approved the project before implementation. The project manager completed weekly monitoring in collaboration with the organization's director of quality improvement.

\section{Quality Improvement Framework and Change Theory}


This DNP project applied the Plan, Do, Study, Act (PDSA) Model as the framework that supported the project's goals after implementation (Institute for Healthcare Improvement, n.d.). Adopting the PDSA model as the framework for this project fostered an environment that encouraged open dialogue and built a culture of safety through each phase to reach the common goal of zero-patient harm. The planning phase highlighted intervention development after receiving organizational feedback and before implementation (Institute for Healthcare Improvement, n. d.). The doing phase identified how to execute necessary changes required for the sustainability of the practice. The study phase analyzed the desired outcomes. Finally, the act phase provided the time to adapt and adopt the changes accepted after implementation and then determined the model's next cycle.

Lewin's Theory of Change (Lewin, 1951) served as this DNP project's foundation and was used to translate evidence-based practice (EBP) recommendations into change within the organization. Lewin's three-step Theory of Change perceives change as achieving an equilibrium between driving and restraining forces that work in opposite directions within an organization (White et al., 2016). Lewin's Theory of Change was applied during the implementation planning phase of this project to help the organization recognize how values, beliefs, perceptions, and behavior patterns led to a change in culture (White et al., 2016). This theory was used as the anchor for the project to unfreeze the organization's current approach to safety, refine organizational behaviors and move towards improvement, and then refreeze the new behaviors (Lewin, 1951).

During project planning, the unfreezing phase prompted disturbances within the organization, which helped propel change within the organization. In this phase, the project manager procured buy-in from stakeholders. The unfreezing phase translated into hospital 
management's support and reinforcement of new practices with frontline staff. The movement phase occurred during project implementation and accounted for the new changes in culture and safety event reporting. This phase led to increased safety event reporting rates within the organization. During the movement phase, the project manager and trained stakeholders provided additional education and reminders to ensure fidelity of practice changes. Finally, the refreezing phase reinforced the sustainability of the practice changes, sustainability, and hospitalwide expansion.

\section{Evidence Search Strategy}

A literature review was completed using the electronic interface EBSCOhost Research Databases. A federated search was accomplished using the databases provided by EBSCOhost. The initial databases included: CINAHL Complete, Health Business Elite, Gale Academic OneFile, Gale General OneFile, Gale OneFile: Health and Medicine, Gale Academic OneFile, Science Direct, Cochrane Database of Systematic Reviews, Credo Reference, Academic Core, DynaMed, MEDLINE, Academic Search Index, and Journals@ Ovid. Keywords addressing the PICOT question were searched via Boolean phrases. The first Boolean phrase included "errors OR incidents OR accidents OR mistakes OR adverse events" (S1). The second Boolean phrase used was "leadership OR administration OR management OR c-suite or executives" (S2). The third Boolean phrase was "zero harm OR no harm OR journey to zero harm" (S3). The next phrase used was “change OR change agent OR transform OR transformation OR development OR translate OR improve OR transition OR improvement OR change management OR behavior change" (S4). The fifth phrase included the keywords "high reliability organizations OR tertiary care center OR healthcare organization OR health care organization OR hospital" (S5). The sixth Boolean phase was "safety program OR program OR stop the line OR campaign or safety stop" 
(S6). The seventh search included "frontline staff OR front line staff OR nursing OR employee OR workforce" (S7). Finally, the last Boolean phrase used to search keywords was "health care quality OR healthcare quality OR healthcare safety OR health care safety OR change in culture OR change of culture OR culture of excellence OR organizational culture OR culture of safety OR safety culture OR just culture (S8).

A Boolean phrase using "search with AND" was then used to search S1 and S2 and S3 and S4 and S5 and S6 and S7 and S8. The search resulted in 7,176 total articles. Filters included source type of academic journals, English language, publication dates between 2015 to 2020, and peer-reviewed. Of the 1,799 studies remaining, results that included "randomized control trial OR rct OR randomised control trial OR randomized controlled trial OR cohort study OR case report OR case control study OR cross-sectional study" were kept. However, studies that included the terms "meta-analysis OR meta analysis OR systematic review OR meta-synthesis or meta synthesis" were excluded, leaving a total number of 129 available study results.

Abstracts and studies were carefully reviewed for relevance according to the following criteria: related to the PICOT question, involved a health care organization, and aimed to reduce incidents, errors, or harm. A total of 22 studies met the criteria and their full text was retrieved and evaluated to determine final eligibility. This process resulted in 18 relevant primary sources.

\section{Evidence Search Results}

The search strategy using Boolean phrases produced a total of 7,176 results. A PRISMA diagram (see Appendix A) was created to illustrate the search strategy used to select the research studies. Full-text versions of the 22 research articles that met all inclusion criteria were carefully reviewed to ensure the evidence addressed the PICOT question. Finally, a total of 18 primary articles were selected at the conclusion of the evidence search. The evidence table (see Appendix 
B) highlights each article selected, the assigned quality and grade, tools or interventions used, and key findings.

Using the Johns Hopkins Nursing Evidence-Based Practice Research Evidence Appraisal Tool (n.d.), each research article was assessed for strength of evidence. All 18 articles were cross-sectional Level III (non-experimental) articles. A total of seven articles were of highquality, 11 were of good-quality, and zero were of low-quality. A diagram (see Appendix C) was created to describe each level of quality.

The seven high-quality articles included sufficient sample size, had definitive conclusions and made consistent recommendations based on the literature (Johns Hopkins, n.d.). The evaluations reported in the seven high-quality articles used valid and reliable tools, such as the Hospital Survey on Patient Safety Culture (HSOPSC) survey by the Agency for Healthcare Research and Quality (AHRQ). The HSPOSC survey is a validated tool produced by the AHRQ to assess patient safety culture in hospitals (AHRQ, 2020). The standard measure, Cronbach's alpha, was used to indicate the reliability and how well their tool had worked in previous studies. The 11 level III good-quality articles used a sufficient sample size and the conclusions drawn were referenced to some scientific evidence (Johns Hopkins University, n.d.). The results were reasonably consistent. No low-quality articles were present in the selected 18 articles. Each article used as evidence to answer the PICOT question provided results that had a sufficient sample size and statistically significant results.

The literature review produced cross-sectional, level III articles that assessed organizational culture to draw conclusions and were primary, non-experimental studies. No systematic reviews or meta-syntheses identified in the literature solely used primary resources, and therefore none were included in the evidence used to answer the PICOT question. 


\section{Themes with Practice Recommendations}

Three overlapping themes were identified as a result of a thorough literature review on how to improve the reporting of safety incidents and errors and the relationship between frontline staff and leadership. These themes included: 1) organizational culture affects the occurrence of incidents and errors; 2) open communication is necessary to improve safety; and, 3) leadership support in promoting patient safety and teamwork.

\section{Importance of Organizational Culture}

Organizational culture is defined as the shared values, beliefs, behavior patterns, and perceptions within an organization (Kumbi et al., 2020). A total of 14 out of the 18 articles (see Appendix B) found the culture of safety within an organizational system produced behavioral norms that promoted safety. The evidence suggested that ineffective or inappropriate organizational culture could create barriers to reporting incidence and errors and could discourage staff from reporting these events due to lack of feedback and fear of consequences (Ahmed et al., 2019). The evidence also proposed fear of litigation, reluctance to report one's own mistakes, insufficient knowledge about event reporting, and lack of adequate follow-up after an incident demonstrates a need for a change within the safety culture of an organization (Figueiredo et al., 2018). The findings supported that emphasis should be placed on a culture of safety, not only to increase awareness about safety incidents and errors, but also to understand the importance of effective reporting, which increases the likelihood of adverse events being identified and reported.

\section{Open Communication}

The second theme identified in the literature review was communication. Open communication was found to be a necessary tool for improving the reporting rates of safety 
incidents and errors and the relationship between frontline staff and leadership. Of the 18 primary articles located in the evidence table (see Appendix B), 17 mentioned effective communication techniques as a critical component in creating an organizational change that would support the reporting of events and foster a trusting relationship between frontline staff and management. The evidence stated open communication between staff members and executive leadership involvement directly affects leadership's response to safety errors and events (Svitlica et al., 2018). The literature also suggested that adequate communication between different departments of a health care organization helped reduce the number of actual incidents and errors and that communication failures within the health care team were the leading causes of near misses (de Brito Paranagua et al., 2015). One study recognized that utilizing a dashboard to standardize quality indicators improved communication within an organization (Patel et al., 2019).

\section{Need for Leader Support}

The third theme identified was the importance of leadership support to improve frontline staff perceptions of leadership responsiveness to safety events. Of the 18 cross-sectional studies, 12 stated leadership's role was directly related to the comfort level of frontline staff reporting adverse events, incidents, errors, or bias. The results, as communicated by the authors, encouraged organizational leaders to implement a consistent safety culture in health care organizations (de Quadros Morrudo et al., 2019). The change in safety culture led staff to recognize that reporting events did not lead to punitive consequences but instead to system changes to ensure the safety of patients and other individuals (de Quadros Morrudo et al., 2019). Common barriers to the effective reporting of safety incidents and errors included lack of communication from leadership about the importance of reporting events, fear of the report being 
used by leadership to discipline another member of the organization, and not receiving follow-up communication from leadership after an incident had been reported (Ahmed et al., 2019).

\section{Practice Recommendations}

Based on a thorough and rigorous review of the literature and evidence grading, 18 highquality primary resources answered the PICOT question and guided recommendations to create an environment that not only cultivates a culture of safety but also improves reporting (see Appendix E). To increase the reporting rates of safety events and improve the relationship between frontline staff and hospital management, the body of evidence recommended: 1) frontline staff need to feel empowered to report safety events; 2) processes and improvements need to include non-punitive methods and encourage the importance of approaching patient safety systematically; and 3) leaders from within the organization need to respond appropriately to safety events and errors with follow-up and a plan of action for frontline staff. The conclusions drawn from the review supported a valid and reliable safety program that incorporated all three recommendations and emphasized the significance of a safety-focused culture would increase safety events reported by frontline staff, build trusting relationships between frontline staff and hospital leadership, and help cultivate a culture of support and safety rather than a culture that places individuals at fault.

Based on the evidence found in the literature, a safety-focused program that requires prompt leadership support is recommended to increase the frequency of safety event reporting. When organizations eliminate intimidating behaviors, respond promptly to fix problems, and communicate effectively, frontline staff develop trust in leadership and start identifying and reporting safety events more frequently (Benedicto, 2017). The evidence recommended prioritizing patient safety from organizational leaders to ensure staff felt supported and events 
are evaluated efficiently (Im \& Aaronson, 2020). Immediate leadership support to safety events without assigning individual blame will help standardize continuous patient safety improvements and propel systematic changes to prevent process breakdowns from reoccurring ( $\operatorname{Im} \&$ Aaronson, 2020).

\section{Setting, Stakeholders, and Systems Change}

The setting of this DNP scholarly project was completed in the emergency department (ED) of a 411-bed, Level II trauma center, serving more than $40 \%$ of the population of Maine (NLH, 2020). The county in which the organization is located is $95.1 \%$ Caucasian, the median household income is 45,302 dollars, and $16.5 \%$ of the population is aged 65 years of age or older (NLH, 2019b). The high school graduation rate is $88.3 \%$ and $34 \%$ of the population holds an associate's degree or higher (NLH, 2019b). According to the community health needs assessment, the top health priorities for the county and state included: 1) mental health; 2) social determinants of health; 3) substance abuse; 4) access to care; and 5) physical activity, nutrition, and weight (NLH, 2019b).

The ED serves approximately 100 people per day and is made up of 28 beds, two trauma bays, and a separate 10-bed holding unit for mental health emergencies (B. Berlin, personal communication, August 13, 2020). It employs 15 physicians, seven physician assistants, 52 registered nurses, and 16 certified nursing assistants (B. Berlin, personal communication, August 13, 2020; NLH, 2020). Three of the 28 total beds are used for urgent care patients during peak hours. There are a total of six additional beds utilized for patients requiring observation less than 24 hours, and supplemental staffing covers an additional 10-bed transition area for boarding patients awaiting inpatient bed placement. The unit provides ten additional beds in a separate space for emergency psychiatric services (B. Berlin, personal communication, August 13, 2020). 
The organization is part of a larger health care system that employs over 12,000 people (NLH, 2020). The system is comprised of ten member hospitals with 987 licensed beds, a single physician-led medical group, eight nursing homes with 585 long-term beds, five emergency transport members, and 37 primary care locations (NLH, 2020). The ED in which the DNP scholarly project was completed makes up approximately $27 \%$ of the system-wide ED visits per year (NLH, 2020).

Key organizational stakeholders included the vice president of nursing and patient care services, the chief medical officer, the director of performance improvement and patient safety, and the associate vice president (AVP) of emergency services. The organization's annual number of sentinel events and the 2019 AHRQ culture of safety and staff engagement survey results have encouraged hospital leadership to focus on cultivating a culture that ultimately prioritizes macrolevel change within the organization. This DNP scholarly project aligned with the organization's goal to create a process change in the ED that could be sustained and implemented hospital-wide. Organizational support was obtained through a project charter and presentation with the key stakeholders to ensure the terminology, process, and implementation plan were cohesive and sustainable.

A SWOT analysis (see Appendix F) was completed to evaluate the strengths and weaknesses of the DNP scholarly project. Internal factors included strong organizational support and a large patient population. Weaknesses in the SWOT analysis included turnover in ED leadership roles. During the planning phase of the project, there was an interim director of emergency services and both the nurse manager and daytime assistant nurse manager roles were unfilled. Additionally, the project had the potential to increase the workload for the frontline staff and leaders involved in the Safety STOP response. External opportunities included increased 
staff satisfaction and improved organizational reimbursement rates from the Center for Medicare and Medicaid (CMS). Additionally, there was an opportunity for improvements in the AHRQ culture of safety and staff engagement survey and improvements in CMS's hospital rating. External threats included the Sars-CoV-2 virus, also known as COVID-19. The virus created an international pandemic (as of March 2020) and had the potential to cause changes in staffing, resources and create an unpredictable number of ED visits. The pandemic created an increase in levels of hospital staff burnout and stress. COVID-19 also restricted travel for the project manager as travel between states was limited. Finally, COVID-19 affected many federal and state laws propelling changes within healthcare organizations.

\section{Change Process Model: Safety STOP}

Safety STOP is a valid and reliable program implemented by PeaceHealth, a large healthcare organization consisting of 10 medical centers and over 16,094 employees in the Northwest area of the U.S. in conjunction with the Moss Adams/Rona Consulting Group in 2018 (PeaceHealth, n.d.). The Safety STOP program was recommended to the organization as the evidence-based change practice model to increase its safety event reporting rates and improve the frontline staff perceptions of management's response to safety events. Safety STOP aligned with the mission and vision of the organization and its goal of achieving $100 \%$ zero harm. PeaceHealth (2019) increased their rates of safety reporting by implementing the Safety STOP program, which required a timely response to potential or actual threats to patients and frontline staff by empowering every member of the organization to speak up when there was or potentially could be a serious harm occurrence (PeaceHealth, 2019).

Both PeaceHealth and the DNP project location were Level-II trauma centers attempting to empower frontline staff to report safety events and improve their culture of safety survey 
scores (PeaceHealth, 2019). The Safety STOP program required both hospital leadership and frontline staff to work together, identify immediate countermeasures, and prevent safety events from occurring or reoccurring. The Safety STOP program implemented at PeaceHealth (2019) increased its reporting rates of safety events, and the rates of serious safety events decreased from an average of 3.0 safety events to 1.5 events per 10,000 patient days in 12 months. The program has also been recognized for reducing the time from safety events to root cause analysis (RCA) and disseminating the action plan to frontline staff (Premier, 2019).

\section{Implementation Plan with Timeline and Budget}

The short-term objectives of the project included increasing the reporting of safety events in the ED and improving frontline staff and hospital caregivers' perceptions of leadership responses to safety events. Long-term objectives include decreasing the number of incidents, errors, and safety and sentinel events in the emergency department, improving the culture of safety and staff engagement survey scores, and increasing the rates of reimbursement from CMS. The Safety STOP program will be utilized as the change process model for this evidence-based practice project to increase safety event reporting and to improve caregiver perceptions of hospital management's response to safety events. The model will be implemented over four weeks in the organization's ED.

The implementation plan began with obtaining stakeholder and organizational support. The DNP project manager provided the vice president of nursing and patient cares services, $\mathrm{CMO}$, and director of quality improvement with a one-page summary (see Appendix G) of the Safety STOP program. The DNP project manager created and presented a PowerPoint presentation (see Appendix $\mathrm{H}$ ) to educate and obtain buy-in from the stakeholders during an inperson meeting to present the online learning modules used to educate frontline staff. The 
organization's nursing education manager uploaded the slides to the hospitals' online learning portal and assigned the learning module to the frontline staff one week before project implementation. The vice president of nursing sent an email to all frontline staff participants on the same day the education was released to provide leadership support, educate staff on the Safety STOP program and timeline, and ask participants to complete the required online learning module. In addition to the email, the project manager attended nursing huddles at the change of shifts to educate frontline staff on the Safety STOP process, tools, and resources, as well as answer frontline staff questions. The online learning module and in-person education during shift huddles guided the project's process to cultivate a culture change that encouraged approaching patient safety systematically without individual or organizational fault.

\section{Activate a Safety STOP}

The first step in the Safety STOP program was to activate a Safety STOP. A Safety STOP guide (see Appendix H-2) was made readily available on the unit for participants to use as a resource for the project process. A list of qualifying events (see Appendix I) was provided in the ED in a common area to remind participants of the events that qualified for a Safety STOP activation. Qualifying events included the following circumstances that: 1) did or could result in harm to a patient or frontline staff; 2) qualified as "Never 29 Events" (see Appendix I) defined by the National Quality Forum; 3) caused delays in treatment that did or could result in serious harm or death; 4) could result in equipment or facility failure that required escalation; or 5) involved a sterile processing failure (PeaceHealth, 2019).

Participants were educated to ensure that patients were stabilized before activating a Safety STOP. Participants alerted their supervisor and sequestered appropriate equipment, medication vials, and packaging associated with the event. 


\section{Immediate Responder Arrives at Scene}

Hospital leadership had a goal of arriving within ten minutes of a Safety STOP activation. During business hours (8:00 am to 5:00 pm Monday through Friday), the house manager, a safety facilitator, and administrator on call (AOC) arrived at the scene to conduct an evaluation of the events and debrief the situations with the frontline staff involved in the incidents. On holidays, weekends, and after-hours, the house manager would respond to the Safety STOP activation, gather the details, and call the AOC to make them aware of the event. The house manager followed the Safety STOP flow sheet for house managers (see Appendix J) to guide them through the Safety STOP process. Upon arrival at the scene, the house manager's role was to ensure both the patient and frontline staff were safe and stable. The safety facilitator's role was to interview the individuals involved in the event and complete the Safety STOP documentation form (see Appendix K).

The house-managers and safety facilitators were educated by the project manager with the support of the vice president of nursing and the director of performance improvement via a two-hour in-person meeting one week before project implementation. Tools shown in Appendix $\mathrm{J}$ and $\mathrm{K}$ were used to guide the house managers through the Safety STOP process. Housemanagers were competent in each step of the Safety STOP process as they were typically the first member of the hospital management team to arrive in the ED when a Safety STOP was activated. The safety facilitator (made up of a member of the risk management or performance improvement team) evaluated the event to determine if the event met reportable criteria as determined by the National Quality Forum (see Appendix H) and completed the Safety STOP Checklist (see Appendix J). The response team worked together to identify if additional team members needed to be called to the scene, such as pharmacists, respiratory therapy, facilities, and 
provide a summary of the event to the appropriate AOC. The house manager facilitated the debrief huddle

\section{Administrator on Call Role at Scene}

The director of performance and quality improvement educated organizational leaders via an in-person presentation on the role of AOC in the Safety STOP process. The goal of this education was to help the AOCs recognize the importance of leadership support and their role in the Safety STOP process. Each AOC learned how to complete each step of the documentation form (see Appendix K), assume the leadership role upon arrival to the scene, initiate a debrief huddle, and present the Safety STOP event details at the organization's daily safety briefing.

\section{Safety STOP Hand-Off}

At the organization's safety briefing, the AOC or safety facilitator would briefly present the information from the event to the group consisting of one leader representative from each department. The event brief included countermeasures utilized after the event and if other departments could be affected. After a Safety STOP event, forms were handed off to risk management, who then completed the process change alert form (see Appendix L), determined if the event qualified as a sentinel event, and triggered a formal RCA, if necessary.

\section{Post Safety STOP Rounding}

Within 24-hours of a Safety STOP event, the AOC on duty during the Safety STOP activation completed Post-Safety STOP rounding in the ED. This rounding served as a check-in with the department and frontline staff after the safety event. The purpose of the AOC rounding was to thank the department for reporting the safety event, create a second opportunity for debriefing, and allow frontline staff to ask follow-up questions to hospital leadership regarding the safety event. 


\section{Project Timeline and Budget}

A project timeline (see Appendix M) and a list of anticipated expenses (see Appendix $\mathrm{N}$ ) were used to ensure proper communication between the project manager and the organization. A two-week site visit was completed from August 17 through August 28, 2020, to evaluate and observe the ED and the organization's culture, obtain stakeholder buy-in, and make organizationspecific revisions to project tools. Approval from the University of St. Augustine's evidencebased practice review committee and the organization's review committee were obtained in September 2020. A baseline survey and education program were completed before project implementation. The Safety STOP project began on October 5, 2020, and ended on October 30, 2020. Data collection was completed prior, during, and post-implementation.

\section{Role of the Project Manager}

The DNP project manager provided education to stakeholders, participants (frontline staff employed in the ED), and those required to respond to Safety STOP activations with the support of the vice president of nursing, CMO, and director of performance improvement. The DNP project manager analyzed the results of the Safety STOP project in collaboration with the director of performance improvement. Project results and recommendations for sustainability were provided to the vice president of nursing and director of performance management after data analysis and evaluation were completed to aid the organization in house-wide adaptability.

\section{Evaluation Design and Measurement of Project Objectives}

The data collected before, during, and after project implementation were used to measure the pre-intervention changes to post-intervention. The project measured: 1) the total number of Safety STOPS activated; 2) the total number of RL reports submitted by frontline staff; and 3) staff's perceptions of hospital management's response to safety events (see Appendix O for 
comparison data). The baseline number of RL reports were collected from the previous year from November 29, 2019 to October 23, 2019. The project manager collected the total number of Safety STOP activations and the total number of RL reports during project implementation from November 29, 2020 to October 23, 2020.

\section{Frontline Staff Perceptions of Hospital Management's Response to Safety Events}

A 15-question five-point Likert scale survey was used to measure frontline staff perceptions of hospital management's response to safety events. The survey link was distributed to participants via email by the vice president of nursing before implementation and at the completion of the four-week implementation period. The baseline survey was distributed on September 28, 2020 and an identical post-intervention survey was distributed on November 2, 2020, after project implementation was completed. Each survey period lasted two weeks.

The survey (see Appendix P) was created by the project manager and gathered ordinal data $(5=$ strongly agree, $4=$ agree, $3=$ neutral/neither agree nor disagree, $2=$ disagree, $1=$ strongly disagree) using a 15-question, Likert scale format. Responses were stored on the Survey Monkey website. The project manager created a unique username and password to access the data. Statistical data was stored on the project manager's password-locked laptop and in a passwordlocked profile on surveymonkey.com. The survey did not collect any personal or organizational identifiers and was completed anonymously.

\section{Results}

Intellectus Statistics (2021) software was utilized with permission from the University of St. Augustine for Health Sciences to determine the statistical significance the Safety STOP program had on frontline staff perceptions of hospital management's response to safety events (see Appendix Q) and the total number of safety events reported. 
A two-tailed-independent samples t-test was conducted on each individual survey question as well as on the mean of the combined responses. The two-tailed independent samples t-test conducted to examine whether the mean of responses were significantly different between the baseline and post-implementation survey was determined not significant $(\mathrm{p}=.595)$, and so the null hypothesis was not rejected. However, question one of the Likert scale survey did show significance (see Table 1). A two-tailed independent samples t-test was conducted to examine whether the mean of question one: Safety is a top priority for hospital management was significantly different between baseline and post-implementation survey. The result of the twotailed independent samples t-test was significant $(p<.001)$, indicating the null hypothesis can be rejected. This finding suggests the mean of question one was significantly different between the baseline and post-implementation surveys. The results are presented in Table 1.

Table 1

Two-Tailed Independent Samples t-Test for Q1: Safety is a top priority of hospital management

\begin{tabular}{lcccccccc}
\hline & \multicolumn{3}{c}{ Pre } & \multicolumn{3}{c}{ Post } & & \\
\multicolumn{1}{c}{ Variable } & $M$ & $S D$ & $M$ & $S D$ & & & $p$ & $d$ \\
\hline $\begin{array}{l}\text { Q1: Safety is a top priority for hospital } \\
\text { management }\end{array}$ & 3.06 & 1.33 & 4.11 & 0.60 & -3.76 & $<.001$ & 1.02 \\
\hline
\end{tabular}

Note. $\mathrm{N}=56$. Degrees of Freedom for the $t$-statistic $=25.93 . d$ represents Cohen's $d$.

This finding suggested the means of survey responses were not significantly different between the baseline and post-implementation categories. The intervention did not significantly impact staff's overall perceptions of hospital management's response to safety events in the ED; however, the Safety STOP program did improve staff perception that safety is a top priority for hospital management.

\section{Reporting Rates of Safety Events Before and After Safety STOP Implementation}


During project implementation, a total of eight Safety STOPs were activated by frontline staff in the ED. A two proportions z-test was conducted to examine whether there was a significant difference between the proportions of safety events reports in 2019 and 2020.

The result of the two proportions z-test was significant $(p=.003)$, indicating the null hypothesis could be rejected. This suggested the proportion of safety events reported during the implementation phase $(n=108)$ was significantly higher than the proportion of safety events reported during the same period one year prior $(n=67)$. This significance indicates the Safety STOP program created an increase in the total number of safety events reported during the implementation period. Table 2 presents the results of the two-sample proportions z-test.

\section{Table 2}

Two Proportions z-Test for the difference between 2019 Safety Stops and 2020 Safety Stops

\begin{tabular}{lrrrrr}
\hline Samples & Responses & $\boldsymbol{N}$ & Proportion & $\boldsymbol{S D}$ & $\boldsymbol{S E}$ \\
\hline 2019_Safety_Stops & 0 & 67 & 0 & 0.00 & 0.00 \\
2020_Safety_Stops & 8 & 103 & 0.08 & 0.27 & 0.03 \\
\hline
\end{tabular}

Note. $z=-2.95, p=.003,95 \%$ CI: $[-0.13,-0.03]$

\section{Clinical Significance}

The Safety STOP program not only created a significant difference in frontline staff's perception that safety is a top priority for hospital management, but it also created clinical significance within the organization. Before implementing the intervention, there were no immediate responses to safety events reported in the ED (except for falls and pressure ulcers). The intervention created an immediate response from hospital leadership to specific safety events in the ED, which led to a significant reduction in response time.

The time saved on investigating safety events days or weeks after they have occurred translated into a decrease in the total dollar amount paid in staff hours to investigate and review each safety event. Additionally, as the total number of reportable sentinel events continues to 
decrease, CMS's total reimbursable rate will increase. The increase in the total number of safety events reported in RL Solutions provided the organization useful information, which has led to both process and quality of care improvements.

\section{Human Rights and Privacy of Health Information}

No patient identifiers were collected or used in the statistical analysis of the results and outcomes. Patient labels that included the patient's name, medical record number and birthday were placed on Safety STOP forms to allow the organization to assess the event and develop a proper plan of action. However, the forms with patient labels were not collected by the project manager and remained in the organization's custody. The project manager received a report of the total number of safety events and safety reports completed from the quality improvement director. The project manager did not collect the Safety STOP forms or safety event reports. Caregiver participation in the baseline and post-intervention surveys was anonymous. The project manager did not collect or store any participant or patient information from the project.

\section{Impact}

The impact of this DNP scholarly project was significant on the organization. As of February 10, 2021, the project was implemented house-wide, and a total of 95 Safety STOPs were activated. The most considerable impacts include; 1) a reduction in the total number of sentinel events required to be reported to the state; 2 ) a decrease in total time from incident to RCA; 3) an increased awareness of safety events by hospital leadership; and 4) an increased total number of safety events reported to RL solutions by staff.

The total number of sentinel events required to be reported to the state has reduced since the Safety STOP implementation (discussion with Directors of Risk Management and Performance Improvement, personal communication, January 27, 2021). Before project 
implementation, the organization struggled to pull together specific details surrounding a safety incident before the state's 48-hour deadline for reporting sentinel events (State of Maine Department of Health and Human Services, 2019). Safety STOP responders collect information from the safety event upon arrival to the scene, and dynamic interviewing of individuals occurs when responders arrive. Before project implementation, staff interviews occurred two to four weeks after an incident, which delayed hospital management's opportunity to collect information promptly, putting the organization at risk. Additionally, the organization has reduced the amount of time from the initial incident to the RCA. Before project implementation, RCA occurred 30, 60, or 90 days after a safety event; however, since the house-wide implementation of Safety STOP, RCA is completed approximately 15-30 days after the incident. Before intervention implementation, RCA and $\mathrm{RCA}^{2}$ were completed during two separate meetings; however, posthouse-wide implementation, it is common for RCA and $\mathrm{RCA}^{2}$ to occur during the same meeting. This streamlined process has increased efficiency and has reduced the total time from the initial incident to an action plan.

The director of performance improvement reported a positive change in safety culture since implementing Safety STOP (Director of Performance Improvement, personal communication, February 10, 2021). The organization reported an increase in positive discussion around safety events. Safety STOP activations that occurred during the previous day are communicated to hospital leadership in the daily safety briefing. The director of risk management and the director of performance improvement meet weekly to discuss new Safety STOP events and follow-up with previous safety events until the incidents are closed.

To maintain Safety STOPs sustainability over time, the organization addressed AOC's response to the Safety STOP events overnight. Two AOCs reported the pages received overnight 
from the house manager were inconvenient. To address this challenge, the organization used the PDSA cycle to improve communication between the house-supervisor and overnight AOC. The organization still requires the AOC to be called for a Safety STOP activation; however, only when an immediate response is required. The purpose of the phone call is to develop a plan of action or receive support the house manager cannot achieve independently without additional resources. Since the project implementation, one employee reported a negative response from the AOC when they activated a Safety STOP. The employee and the AOC involved in the incident were counseled by executive leadership to maintain the positive change in the safety culture created by the intervention. Additionally, the organization's president began sending a card thanking each individual who activated a Safety STOP, which has created a sense of positive reinforcement surrounding safety events.

\section{Limitations}

The study's limitations included the COVID-19 pandemic, leadership turnover in the ED, and low participation rate in the post-implementation survey. The implementation period of the project occurred during the 2020 COVID-19 pandemic. COVID-19 impacted the organization by fluctuating the number of patients seeking ED care during the months of implementation and requiring frontline staff to be out of work due to acquiring COVID-19 or presenting COVID-19 symptoms. New hospital regulations required staff to wear personal protective equipment for extended periods creating increased workload and decreased motivation. The pandemic required the organization to re-allocate resources and make adjustments to fiscal year budgets.

During project planning, there was an interim director of the ED, and the nurse manager and daytime assistant nurse manager positions were vacant. A new ED director began employment during the first week of project implementation. This turnover may have created a 
positive or negative impact on shareholder and staff buy-in , as well as, participation. Finally, this study had an implementation period of four weeks and survey periods over two weeks. The study would have benefited from an extended implementation phase and survey period to account for the impact of COVID-19 on staff. Despite limitations presented during the implementation period, Safety STOP was sustained in the ED, and the project has been implemented house-wide by the organization.

\section{Dissemination Plan}

The DNP project manager shared all results and outcomes of this DNP scholarly project with the organization via an online PowerPoint presentation. The vice president of nursing, director of performance improvement, director of risk management, and the research and evidence-based practice nurse liaison will receive a copy of the final DNP scholarly paper via email. The results will be used to maintain sustainable hospital-wide implementation. The DNP project manager has provided the organization with all of the educational materials and tools used during project implementation.

This DNP scholarly paper will be submitted to SOAR@USA institutional repository to showcase the scholarly work publicly. The abstract will be used to apply for publication in a professional healthcare journal. Potential journals include the Journal of Emergency Nursing or Nurse Leader. Additional journal categories are journals of nursing, health care safety, health care administration, or health care leadership. Publication of the scholarly paper will disseminate outcomes and results to other nurse leaders and health care organizations looking to improve reporting rates of safety events. The DNP project manager may also apply to present the scholarly project at regional or national conferences such as the Emergency Nurses Association.

\section{Conclusion}


The intention of this DNP scholarly project was to improve the reporting rates of safety events in the ED and to improve frontline staff perceptions of hospital management's response to safety events. The Safety STOP program achieved the intended outcomes in four weeks and improved both staff perception that safety is a top priority for hospital management and created a significant increase in the proportion of safety events reported in the ED. The intervention did not significantly impact staff's overall perceptions of hospital management's response to safety events in the ED. However, the Safety STOP program cultivated a change in safety culture by improving leadership's response to safety events, reduced the total number of sentinel events, and improved the time of the incident to the action plan. 


\section{References}

Agency for Healthcare Research and Quality (AHRQ). (2020). Surveys on patient safety culture (SOPS) hospital survey. https://www.ahrq.gov/sops/surveys/hospital/index.html

Ahmed, Z., Saada, M., Jones, A. M., \& Al-Hamid, A. M. (2019). Medical errors: Healthcare professionals' perspective at a tertiary hospital in Kuwait. PLOS ONE, 14(5). ISSN: 19326203

Benedicto, A. M. (2017). Safety culture: The highest priority for healthcare executives: The first stop on the journey to high reliability is making it the only priority. Healthcare Executive, 32(4), 66-68. ISSN: 0883-5381

de Brito Paranagua, T. T., Queiroz Bezerra, A. L., \& de Camargo Silva, A. E. (2015). The occurrence of near misses and associated factors in the surgical clinic of a teaching hospital. Cogitare Enfermagen, 20(1), 120-127. ISSN: 1414-8536

de Quadros Morrudo, E., Digueiredo, P. P., Silveira, R. S., Barlem, J.T., Oliveira, S. G., \& Ramos, F. C. (2019). Errors in medicinal therapy and the consequences for nurisng. Cuidado Fundamental, 11(1), 88-96. http://doi.org/10.9789/2175-361.2019.v11i1.88-96

Figueiredo, L. M., de Oliveira, E. S., Silvana, C., Santos Figeiredo Brito, M. F., D'Innocenzo, M. (2018). Analysis of incidents notified in a general hospital. Revista Brasileira de Enfermagem, 71(1), 111-119. http://doi.org/10.1590/0034-7167-2016-0574

Im, D. \& Aaronson, E. (2020). Best practices in patient safety and communication. Emergency Department Operations and Administration. 38(3), 693-703. https://doi.org/10.1016/j.emc.2020.04.007

Institute for Healthcare Improvement. (n. d.). Plan-Do-Study-Act worksheet. http://www.ihi.org/resources/Pages/Tools/PlanDoStudyActWorksheet.aspx 
Intellectus Statistics [Online computer software]. (2021). Intellectus statistics.

https://analyze.intellectusstatistics.com/

Kaiser Family Foundation. (2020). Look up your hospital: Is it being penalized by Medicare? https://khn.org/news/hospital-penalties/

Kumbi, M., Hussen, A., Lette, A., Nuriye, S., \& Morka, G. (2020). Patient safety culture and associated factors among healthcare factors among health care providers in Bale Zone hospitals, Southeast Ethiopia: An institutional based cross-sectional study. Dove Medical Press Limited. http://doi.org/10.2147/DHPS.S198146

Lewin, K. (1951). Field theory of social science: Selected theoretical papers. The Annals of the American Academy of Political and Social Science, 276(1), 146-147.

Meyer, H. (2019). Hospitals fall short of patient-safety goals 20 years after "To Err is Human." Modern Healthcare, 49(44), 18-18.

Northern Light Health (NLH). (2020). About us. https://northernlighthealth.org/Locations/Eastern-Maine-Medical-Center/About-Us

Northern Light Health (NLH). (2019a, November 15). EMMC \& practices: 2019 culture of safety survey results.

Northern Light Health (NLH). (2019b). 2019 Maine shared community health needs assessment: Penobscot County. https://northernlighthealth.org/getattachment/Community-HealthNeeds-Assessment/2019-CHNA-Reports/Penobscot_2019CHNA_FINAL.pdf.aspx?lang=en-US

Novak, A. (2019). Improving safety through speaking up: An ethical and financial imperative. Journal of Healthcare Risk Management, 39(1), 19-27. https://doi.org/10.1002/jhrm.21360 
PeaceHealth. (2019). Safety STOP: Redefining possible for PeaceHealth.

PeaceHealth. (n.d.). PeaceHealth at a glance.

https://www.peacehealth.org/sites/default/files/systemwidepeacehealth_at_a_glance_202 0.pdf

Patel, M. S., Rathi, B., Tashfeen, K., \& Yarubi, M. A. (2019). Development of implementation of maternity dashboard in regional hospital for quality improvement at ground level: A pilot study. Oman Medical Journal, 34(3), 194-99. http://doi.org/10.5001/omj.2019.38

Polonsky, M. S. (2019). High-reliability organizations: The next frontier in healthcare quality and safety. Journal of Healthcare Management, 64, 4, 213-221. https://doi.org/10.1097/JHM-D-19-00098

Premier.(2019). QUEST 2020 priority intensive: Safety, risk and human factors. Part 10: Safety STOP-A breakthrough pathway for patient safety.

Sivanandy, P., Maharajan, M. K., Wei, T. T., Loon, T. W., \& Yee, L. C. (2020). Evaluation of patient safety culture among Malaysian retail pharmacists: Results of self-reported study. Patient Preference and Adherence, 1317-1326. http://doi.org/10.2147/PPA.S111537

State Maine Department of Health and Human Services. (2019). Maine sentinel event notification and near miss reporting form. https://www.maine.gov/dhhs/dlc/safetyreporting/sentinel-events

Svitlica, B. B., Milutinovic, D., Bozic, A., Maletin, S., \& Lalic, I. (2018). The assessment of patient safety culture: The psychometric study of the Serbian version of the questionnaire hospital survey on patient safety culture. Medicinski Pregled, 71(1), 45-52. http://doi.org/10.2298/MPNS18S1045B 
The Johns Hopkins University. (n.d.). Johns Hopkins nursing evidence-based practice research evidence appraisal tool. https://www.mghpcs.org/EED_Portal/Documents/PI_EBP/Jon_Hopikins_Tools/Research _Evidence_Appraisal_Tool_fillable.pdf

White, K. M., Dudley-Brown, \& Terhaar, M. F. (2016). Translation of evidence into nursing and health care. ( $2^{\text {nd }}$ ed.). Springer Publishing Company, LLC 


\section{Appendix A}

\section{PRISMA Diagram}

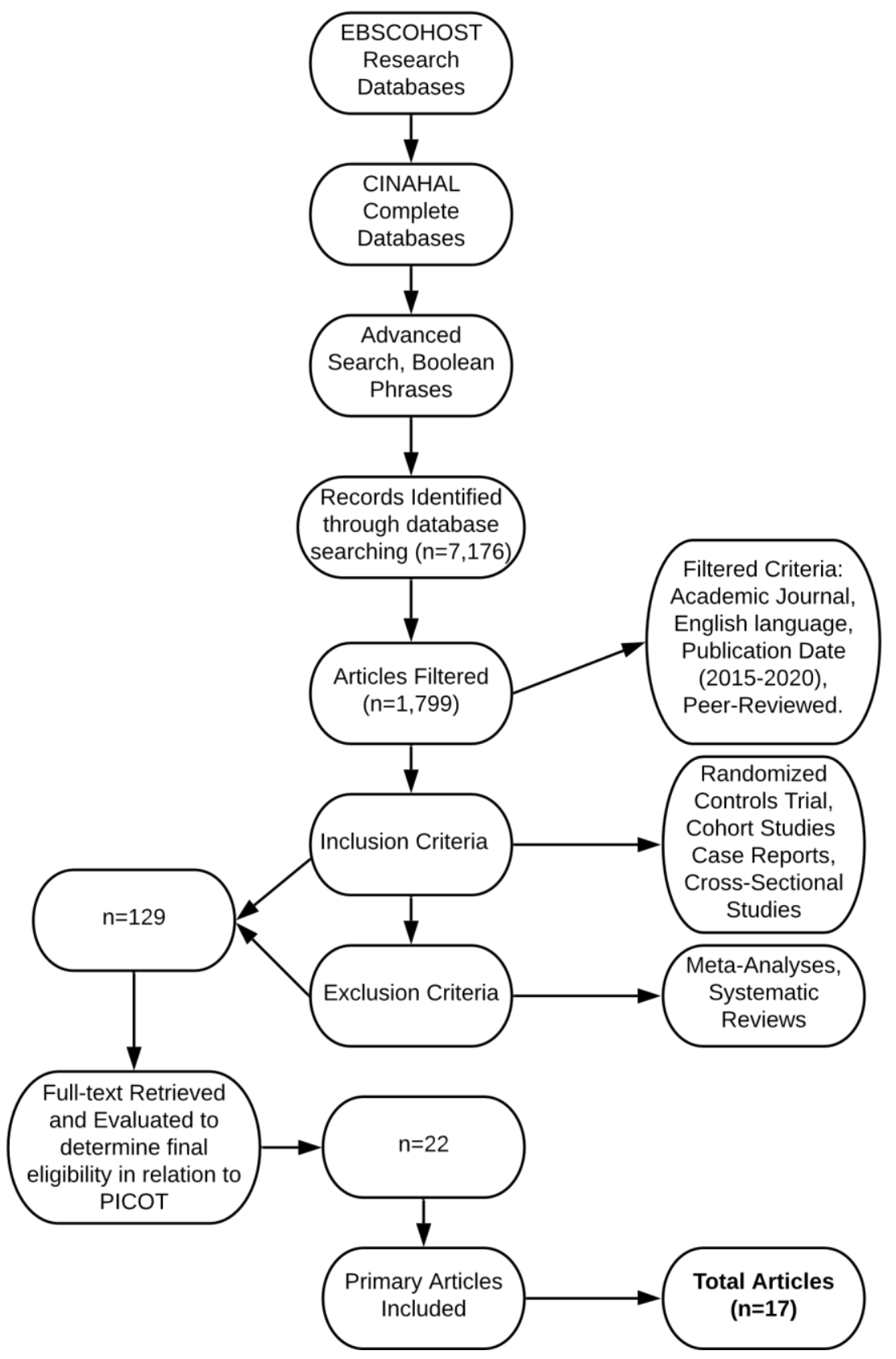


Appendix B

\begin{tabular}{|c|c|c|c|c|c|}
\hline \multicolumn{6}{|c|}{ Evidence Table } \\
\hline & Citation & Design & $\begin{array}{l}\text { Level/ } \\
\text { Quality }\end{array}$ & $\begin{array}{l}\text { Tools, } \\
\text { Intervention }\end{array}$ & Key Findings \\
\hline 1 & $\begin{array}{l}\text { Kumbi, M., Hussen, A., } \\
\text { Lette, A., Nuriye, S., } \\
\text { Morka, G. (2020). Patient } \\
\text { safety culture and } \\
\text { associated factors among } \\
\text { healthcare factors among } \\
\text { health care providers in } \\
\text { Bale Zone hospitals, } \\
\text { Southeast Ethiopia: An } \\
\text { institutional-based cross- } \\
\text { sectional study. Dove } \\
\text { Medical Press Limited. } \\
\text { http://dx.doi.org/10.2147/ } \\
\text { DHPS.S198146 }\end{array}$ & $\begin{array}{l}\text { Cross- } \\
\text { sectional } \\
\text { study, } \\
\text { facility- } \\
\text { based, } \\
\text { over } 30 \\
\text { days. }\end{array}$ & $\begin{array}{l}\text { Level } \\
\text { III/Good } \\
\text { Quality }\end{array}$ & $\begin{array}{l}\text { Self- } \\
\text { administered } \\
\text { questionnaire. } \\
\text { A survey } \\
\text { called the } \\
\text { "Hospital } \\
\text { Survey on } \\
\text { Patient Safety } \\
\text { Culture" was } \\
\text { used to collect } \\
\text { data } \\
\text { (developed by } \\
\text { AHRQ) }\end{array}$ & $\begin{array}{l}\text { Patient safety scores were } \\
\text { lower than the recommended } \\
\text { standard by AHRQ. Well- } \\
\text { designed patient safety } \\
\text { interventions are needed to } \\
\text { be integrated with } \\
\text { organizational policies } \\
\text { addressing all dimensions of } \\
\text { patient safety culture. }\end{array}$ \\
\hline 2 & $\begin{array}{l}\text { Svitlica, B. B., } \\
\text { Milutinovic, D., Bozic, } \\
\text { A., Maletin, S., \& Lalic, } \\
\text { I. (2018). The assessment } \\
\text { of patient safety culture- } \\
\text { the psychometric study of } \\
\text { the Serbian version of the } \\
\text { questionnaire hospital } \\
\text { survey on patient safety } \\
\text { culture. Medicinski } \\
\text { Pregled, 71(1), 45-52. } \\
\text { 10.2298/MPNS18S1045B }\end{array}$ & $\begin{array}{l}\text { Cross- } \\
\text { sectional } \\
\text { study. } \\
\text { Response } \\
\text { rate was } \\
1,435 .\end{array}$ & $\begin{array}{l}\text { Level } \\
\text { III/High } \\
\text { Quality }\end{array}$ & $\begin{array}{l}\text { The "Hospital } \\
\text { Survey on } \\
\text { Patient Safety } \\
\text { Culture" was } \\
\text { used to collect } \\
\text { data } \\
\text { (developed by } \\
\text { AHRQ). } 42 \\
\text { questions via } \\
\text { Likert Scale. }\end{array}$ & $\begin{array}{l}\text { Respondents reported good } \\
\text { teamwork on their unit but a } \\
\text { lack of wiliness to work with } \\
\text { colleagues from other units. } \\
\text { Nurses express a negative } \\
\text { opinion about their } \\
\text { relationship with physicians } \\
\text { and other nurses. There is a } \\
\text { need for open } \\
\text { communication among } \\
\text { healthcare workers to } \\
\text { improve safety. Human will } \\
\text { cause errors-determining } \\
\text { how the error occurred is } \\
\text { key. }\end{array}$ \\
\hline 3 & $\begin{array}{l}\text { Ahmed, Z., Saada, M., } \\
\text { Jones, A. M., \& Al- } \\
\text { Hamid, A. M. (2019). } \\
\text { Medical errors: } \\
\text { Healthcare professionals' } \\
\text { perspective at a tertiary } \\
\text { hospital in Kuwait. PLoS } \\
\text { ONE, 14(5). ISSN: 1932- } \\
6203\end{array}$ & $\begin{array}{l}\text { Cross- } \\
\text { sectional } \\
\text { study, } \\
\text { quantitativ } \\
\text { e. Random } \\
\text { sampling. } \\
206 \\
\text { participant } \\
\text { s. }\end{array}$ & $\begin{array}{l}\text { Level } \\
\text { III/Good } \\
\text { Quality }\end{array}$ & $\begin{array}{l}\text { Self- } \\
\text { administered } \\
\text { open and } \\
\text { closed-ended } \\
\text { questionnaire. }\end{array}$ & $\begin{array}{l}57 \% \text { of medical errors occur } \\
\text { in the emergency department } \\
\text { concluding that E.D.s are } \\
\text { should be targeted to reduce } \\
\text { the number of incidents and } \\
\text { errors. } 54.7 \% \text { of the } \\
\text { participants stated that they } \\
\text { do not report incidents due } \\
\text { to organizational culture, } \\
\text { lack of knowledge, and } \\
\text { complex incident reporting } \\
\text { forms. Other reasons include } \\
\text { not receiving follow-up from } \\
\text { the incident report and fear }\end{array}$ \\
\hline
\end{tabular}




\begin{tabular}{|c|c|c|c|c|c|}
\hline & & & & & $\begin{array}{l}\text { of liability and legal action } \\
\text { Recommends increasing } \\
\text { awareness of the need for } \\
\text { incident reporting and } \\
\text { improve the reporting } \\
\text { process. }\end{array}$ \\
\hline 4 & $\begin{array}{l}\text { Sivanandy, P., } \\
\text { Maharajan, M. K., Wei, } \\
\text { T. T., Loon, T. W., \& } \\
\text { Yee, L. C. (2020). } \\
\text { Evaluation of patient } \\
\text { safety culture among } \\
\text { Malaysian retail } \\
\text { pharmacists: Results of } \\
\text { self-reported study. } \\
\text { Patient Preference and } \\
\text { Adherence, 1317-1326. } \\
\text { http://dx.doi.org/10.2147/ } \\
\text { PPA.S111537 }\end{array}$ & $\begin{array}{l}\text { Cross- } \\
\text { sectional } \\
\text { study. The } \\
\text { response } \\
\text { rate was } \\
1,435 .\end{array}$ & $\begin{array}{l}\text { Level } \\
\text { III/High } \\
\text { Quality }\end{array}$ & $\begin{array}{l}\text { Non- } \\
\text { interventional } \\
\text { surveys. The } \\
\text { Pharmacy } \\
\text { Survey on } \\
\text { Patient Safety } \\
\text { Culture } \\
\text { (PSOPSC) } \\
\text { questionnaire. } \\
36 \\
\text { questions. } \\
\text { Cronbach's } \\
\text { [alpha] } \\
\text { showed tool } \\
\text { valid and } \\
\text { reliable. }\end{array}$ & $\begin{array}{l}\text { The pharmacy environment } \\
\text { is a significant factor related } \\
\text { to dispensing errors. A } \\
\text { continuous learning culture } \\
\text { will reduce errors. Effective } \\
\text { communication is very } \\
\text { important. Team-members } \\
\text { with a high-level } \\
\text { understanding are willing to } \\
\text { admit their mistakes and } \\
\text { accept feedback. Being able } \\
\text { to talk about and become } \\
\text { aware of errors will promote } \\
\text { patient safety. Root cause } \\
\text { analysis should be utilized to } \\
\text { determine the underlying } \\
\text { cause of the error. }\end{array}$ \\
\hline 5 & $\begin{array}{l}\text { Patel, M. S., Rathi, B., } \\
\text { Tashfeen, K., \& Yarubi, } \\
\text { M. A. (2019). } \\
\text { Development of } \\
\text { implementation of } \\
\text { maternity dashboard in } \\
\text { regional hospital for } \\
\text { quality improvement at } \\
\text { ground level: A pilot } \\
\text { study. Oman Medical } \\
\text { Journal, 34(3), 194- } \\
\text { 199.http://dx.doi.org/10.5 } \\
\text { 001/omj.2019.38 }\end{array}$ & $\begin{array}{l}\text { Prospectiv } \\
\text { e, cross- } \\
\text { sectional } \\
\text { study. }\end{array}$ & $\begin{array}{l}\text { Level III/ } \\
\text { Low } \\
\text { quality. }\end{array}$ & $\begin{array}{l}\text { Maternity } \\
\text { Dashboard, } \\
\text { automated. }\end{array}$ & $\begin{array}{l}\text { The use of a dashboard } \\
\text { allowed the study to } \\
\text { determine that the healthcare } \\
\text { facility was overbooked, had } \\
\text { insufficient staff, and too } \\
\text { many young doctors } \\
\text { compared to experienced } \\
\text { doctors. Recommends } \\
\text { standardization of quality } \\
\text { indicators. A dashboard can } \\
\text { improve patient safety and } \\
\text { quality of care. }\end{array}$ \\
\hline 6 & $\begin{array}{l}\text { Omidi, L., Akbari, R., } \\
\text { Hadavandi, E., \& Zarei, } \\
\text { E. (2019). An intelligent } \\
\text { algorithm for assessing } \\
\text { patient safety culture and } \\
\text { adverse events voluntary } \\
\text { reporting using PCA and } \\
\text { ANFIS. International } \\
\text { Journal of Risk and } \\
\text { Safety, 30(1), 45-58. DOI: } \\
\text { 10.3233/JRS-180036 }\end{array}$ & $\begin{array}{l}\text { Cross- } \\
\text { sectional, } \\
311 \\
\text { participant } \\
\text { s. }\end{array}$ & $\begin{array}{l}\text { Level } \\
\text { III/High } \\
\text { Quality }\end{array}$ & $\begin{array}{l}\text { HSOPSC } \\
\text { questionnaire } \\
\text { and a two-part } \\
\text { questionnaire. } \\
\text { Assessed 12- } \\
\text { dimensions of } \\
\text { patient safety. }\end{array}$ & $\begin{array}{l}\text { Half of the participants have } \\
\text { experienced a medical error } \\
\text { or adverse event. Less than } \\
50 \% \text { of participants } \\
\text { voluntarily reported their } \\
\text { medical errors. About } 50 \% \\
\text { of participants have } \\
\text { experienced a medical error } \\
\text { in the } 12 \text {-months before the } \\
\text { survey-organizational } \\
\text { culture affects error rates. }\end{array}$ \\
\hline
\end{tabular}




\begin{tabular}{|c|c|c|c|c|c|}
\hline 7 & $\begin{array}{l}\text { Lopes de Figueiredo, M., } \\
\text { de Oliveira, E. S., } \\
\text { Silvana, C., Santos } \\
\text { Figeiredo Brito, M. F., } \\
\text { D'Innocenzo, M. (2018). } \\
\text { Analysis of incidients } \\
\text { notifed in a general } \\
\text { hospital. Revista } \\
\text { Brasileira de } \\
\text { Enfermagem, 71(1), 111- } \\
\text { 119. } \\
\text { http://dx.doi.org/10.1590/ } \\
\text { 0034-7167-2016-0574 }\end{array}$ & $\begin{array}{l}\text { Retrospect } \\
\text { ive, } \\
\text { descriptiv } \\
\text { e, } \\
\text { quantitativ } \\
\text { e. Random } \\
\text { samples.1, } \\
316 \\
\text { incidents } \\
\text { reviewed. }\end{array}$ & $\begin{array}{l}\text { Level } \\
\text { III/High } \\
\text { Quality }\end{array}$ & $\begin{array}{l}\text { Electronic } \\
\text { notification } \\
\text { forms of } \\
\text { incidents and } \\
\text { errors were } \\
\text { reviewed. }\end{array}$ & $\begin{array}{l}\text { The most reported type of } \\
\text { errors are those related to the } \\
\text { medication supply chain, } \\
\text { followed by pressure ulcers, } \\
\text { and failures during } \\
\text { techniques, procedures, and } \\
\text { transfers. Emergency } \\
\text { department is overall the } \\
\text { largest area for incidents and } \\
\text { errors to occur. Punitive } \\
\text { culture still exists. } \\
\text { Communication barriers } \\
\text { imply greater adverse events. }\end{array}$ \\
\hline 8 & $\begin{array}{l}\text { Karimi, F. Z., } \\
\text { Ebrahimipour, H., } \\
\text { Hooshman, E., Bayrami, } \\
\text { R., Pourshirazi, M., Afiat, } \\
\text { M; Esmaili, H., \& } \\
\text { Vafaee-Najar, A. (2016). } \\
\text { Medication errors and its } \\
\text { contributing factors } \\
\text { among midwives. Journal } \\
\text { of Midwifery and } \\
\text { Reproductive Health, } \\
\text { 4(4), 784-756. } \\
\text { http://dx.doi.org/10.2203 } \\
\text { 8/jmrh.2016.7563 }\end{array}$ & $\begin{array}{l}\text { Descriptiv } \\
\text { e, cross- } \\
\text { sectional } \\
\text { study. } 79 \\
\text { participant } \\
\text { s } \\
\text { completed } \\
\text { the } \\
\text { survey. }\end{array}$ & $\begin{array}{l}\text { Level } \\
\text { III/Good } \\
\text { Quality }\end{array}$ & $\begin{array}{l}\text { A } \\
\text { questionnaire } \\
\text { consisting of } \\
\text { four sections, } \\
\text { Likert Scale. } \\
\text { Reliability and } \\
\text { validity of the } \\
\text { tool confirmed } \\
\text { by previous } \\
\text { studies. } \\
\text { Cronbach's } \\
\text { alpha used for } \\
\text { evaluation. }\end{array}$ & $\begin{array}{l}\text { Overcrowding of unit, fear } \\
\text { of authorities, and attributing } \\
\text { the medication error to } \\
\text { individual factors were the } \\
\text { main reason against } \\
\text { reporting medication errors. } \\
\text { More attention should be } \\
\text { paid to error reporting } \\
\text { systems and education. }\end{array}$ \\
\hline 9 & $\begin{array}{l}\text { Yaprak, E. \& Intepeler, S. } \\
\text { S. (2015). Factors } \\
\text { affecting the attitudes of } \\
\text { health care professionals } \\
\text { toward medical errors in a } \\
\text { public hospital in Turkey. } \\
\text { International Journal of } \\
\text { Caring Sciences, } 8(3) \text {, } \\
\text { 647-655. ISSN: 1791- } \\
\text { 5201 }\end{array}$ & $\begin{array}{l}\text { Descriptiv } \\
\text { e, cross- } \\
\text { sectional } \\
\text { study. } 652 \\
\text { participant } \\
\text { s. }\end{array}$ & $\begin{array}{l}\text { Level } \\
\text { III/High } \\
\text { Quality }\end{array}$ & $\begin{array}{l}\text { Sociodemogra } \\
\text { phic and } \\
\text { Working } \\
\text { Characteristics } \\
\text { questionnaire } \\
\text { From and } \\
\text { Medical } \\
\text { Errors } \\
\text { Attitude Scale. } \\
\text { Likert Scales. } \\
\text { Cronbach's } \\
\text { alpha.66. } \\
\end{array}$ & $\begin{array}{l}\text { All managers at all levels, } \\
\text { along with healthcare } \\
\text { professionals, should be } \\
\text { encouraged to participate in } \\
\text { education programs based on } \\
\text { improvements in patient } \\
\text { safety in healthcare. The } \\
\text { participant's perception of } \\
\text { medical errors is negative. }\end{array}$ \\
\hline $\begin{array}{l}1 \\
0\end{array}$ & $\begin{array}{l}\text { de Brito Paranagua, T. T., } \\
\text { Queiroz Bezerra, A. L., \& } \\
\text { de Camargo Silva, A. E. } \\
\text { (2015). The occurrence of } \\
\text { near misses and } \\
\text { associated factors in the } \\
\text { surgical clinic of a } \\
\text { teaching hospital. } \\
\text { Cogitare Enfermagen, } \\
\text { 20(1), 120-127. ISSN: } \\
\text { 1414-8536 }\end{array}$ & $\begin{array}{l}\text { Retrospect } \\
\text { ive cohort } \\
\text { transversal } \\
\text { study. } 750 \\
\text { medical } \\
\text { records } \\
\text { were } \\
\text { reviewed. }\end{array}$ & $\begin{array}{l}\text { Level } \\
\text { III/Good } \\
\text { Quality }\end{array}$ & $\begin{array}{l}\text { The Open Epi } \\
\text { Calculation } \\
\text { tool was used } \\
\text { to determine a } \\
\text { sample size } \\
\text { that represents } \\
\text { the total } \\
\text { population. } \\
\text { The } \\
\text { questionnaire } \\
\text { was used }\end{array}$ & $\begin{array}{l}\text { The development of the } \\
\text { culture of recording } \\
\text { incidents must be } \\
\text { encouraged. Resources } \\
\text { should be directed towards } \\
\text { preventative factors. } \\
\text { Adequate communication } \\
\text { between different } \\
\text { departments of a hospital can } \\
\text { reduce the number of near } \\
\text { misses. Lack of training } \\
\text { leads to more incidents and }\end{array}$ \\
\hline
\end{tabular}




\begin{tabular}{|c|c|c|c|c|c|}
\hline & & & & $\begin{array}{l}\text { before and } \\
\text { after the pilot. }\end{array}$ & $\begin{array}{l}\text { errors. There is scarcity in } \\
\text { the literature regarding } \\
\text { reporting near misses and } \\
\text { studying failures and } \\
\text { preventative actions. }\end{array}$ \\
\hline $\begin{array}{l}1 \\
1\end{array}$ & $\begin{array}{l}\text { Top, M.\& Tekingunduz, } \\
\text { S. (2015). Patient safety } \\
\text { culture in a Turkish } \\
\text { public hospital: A study } \\
\text { of nurse's perception } \\
\text { about patient safety. } \\
\text { Systemic Practice and } \\
\text { Action Research, 28(2), } \\
\text { 87-110. DOI: } \\
\text { 10.1007/s11213-014- } \\
9320-5\end{array}$ & $\begin{array}{l}\text { Cross- } \\
\text { sectional } \\
\text { study. } \\
\text { Participati } \\
\text { on rate } \\
300 .\end{array}$ & $\begin{array}{l}\text { Level } \\
\text { III/High } \\
\text { Quality }\end{array}$ & $\begin{array}{l}\text { HSOPSC } \\
\text { questionnaire, } \\
\text { developed by } \\
\text { AHRQ. }\end{array}$ & $\begin{array}{l}\text { The frequency of event } \\
\text { reporting about medical } \\
\text { errors was low. Units with } \\
\text { supervisor/manager support } \\
\text { and expectations, promoting } \\
\text { patient safety and teamwork } \\
\text { had the highest rates of } \\
\text { positive responses. Staffing } \\
\text { problems can lead to lower } \\
\text { rates of incident reporting. } \\
\text { Proper communication is } \\
\text { essential to eliminating } \\
\text { threats to the safety of } \\
\text { patients in hospital settings. } \\
\text { Reporting of events, non- } \\
\text { punitive policies, with } \\
\text { respect to error reporting, } \\
\text { open communication, and } \\
\text { leadership support for safety } \\
\text { culture may help guide } \\
\text { proactive strategies to } \\
\text { decrease incidents and } \\
\text { errors. }\end{array}$ \\
\hline $\begin{array}{l}1 \\
2\end{array}$ & $\begin{array}{l}\text { Sendlhofer, G., Gombotz, } \\
\text { V., Tiefenbacker, P., } \\
\text { Leitgeb, K., \& Brunner, } \\
\text { G. (2018). 6th grazer risk } \\
\text { day: The future of } \\
\text { yesterday in healthcare. } \\
\text { Safety in Health, 4(1). } \\
\text { ISSN: 2056-5917 }\end{array}$ & $\begin{array}{l}\text { Retrospect } \\
\text { ive Cohort } \\
\text { study. } 683 \\
\text { cases } \\
\text { reviewed. } \\
283 \text { used } \\
\text { for study. }\end{array}$ & $\begin{array}{l}\text { Level } \\
\text { III/Good } \\
\text { Quality }\end{array}$ & $\begin{array}{l}\text { Electronic } \\
\text { Critical } \\
\text { Incident } \\
\text { Reporting } \\
\text { System } \\
\text { (CIRS). }\end{array}$ & $\begin{array}{l}\text { Nurses reported into CIRS } \\
\text { more than physicians. } \\
\text { Largest percentage of cases } \\
\text { were reported by surgical } \\
\text { disciplines. Reasons for } \\
\text { under reporting of events is } \\
\text { diverse. There is fear for } \\
\text { punitive repercussions. }\end{array}$ \\
\hline $\begin{array}{l}1 \\
3\end{array}$ & $\begin{array}{l}\text { de Quadros Morrudo, E., } \\
\text { Digueiredo, P. P., } \\
\text { Silveira, R. S., Barlem, } \\
\text { J.T., Oliveira, S. G., \& } \\
\text { Ramos, F. C. (2019). } \\
\text { Errors in medicinal } \\
\text { therapy and the } \\
\text { consequences for nursing. } \\
\text { Cuidado Fundamental, } \\
\text { 11(1), 88-96. } \\
\text { http://dx.doi.org/10.9789/ } \\
\text { 2175- } \\
\text { 5361.2019.v11i1.88-96 }\end{array}$ & $\begin{array}{l}\text { Descriptiv } \\
\text { e- } \\
\text { explorator } \\
\text { y cross- } \\
\text { sectional } \\
\text { study with } \\
\text { qualitative } \\
\text { approach. } \\
26 \\
\text { participant } \\
\text { s (total of } \\
\text { four } \\
\text { nurses). }\end{array}$ & $\begin{array}{l}\text { Level } \\
\text { III/Low } \\
\text { (sample } \\
\text { size of } \\
\text { nurses). }\end{array}$ & $\begin{array}{l}\text { Semi- } \\
\text { structured } \\
\text { interviews } \\
\text { analyzed } \\
\text { through the } \\
\text { Bardin } \\
\text { Content } \\
\text { Analysis. }\end{array}$ & $\begin{array}{l}\text { A more consistent safety } \\
\text { culture in health institutions } \\
\text { is necessary to reduce errors. } \\
\text { When analyzing errors, } \\
\text { personifying the error to } \\
\text { those who committed it } \\
\text { directly should not occur. } \\
\text { Many staff deny the } \\
\text { existence of errors occurring } \\
\text { when initially questioned. } \\
\text { Many participates were not } \\
\text { aware of the errors occurring } \\
\text { within their organization. } \\
\text { When staff was made aware } \\
\text { that errors were not being }\end{array}$ \\
\hline
\end{tabular}




\begin{tabular}{|c|c|c|c|c|c|}
\hline & & & & & $\begin{array}{l}\text { recorded, they openly states } \\
\text { that some cases of errors do } \\
\text { occur. }\end{array}$ \\
\hline $\begin{array}{l}1 \\
4\end{array}$ & $\begin{array}{l}\text { Hee-Eun, J., Yeongsuk, } \\
\text { S., \& Hee-Young, K. } \\
\text { Nurses' perception of } \\
\text { patient safety culture and } \\
\text { Safety control in patient } \\
\text { safety management } \\
\text { activities. Journal of } \\
\text { Korean Academy of } \\
\text { Nursing Administration, } \\
\text { 23(4), 450-451. } \\
\text { https://doi.org/10.11111/j } \\
\text { kana.2017.23.4.450 }\end{array}$ & $\begin{array}{l}\text { Cross- } \\
\text { sectional } \\
\text { study. } 222 \\
\text { nurses } \\
\text { participate } \\
\text { d }\end{array}$ & $\begin{array}{l}\text { Level } \\
\text { III/Good } \\
\text { Quality }\end{array}$ & $\begin{array}{l}\text { Structured } \\
\text { questionnaire. }\end{array}$ & $\begin{array}{l}\text { Nurses feel that they are not } \\
\text { able to modify their work } \\
\text { conditions to make it safer. } \\
\text { Placing employees on safety } \\
\text { committees can encourage } \\
\text { staff to feel ownership of } \\
\text { safety and participate in } \\
\text { improving the environment. } \\
\text { Majority of incidents } \\
\text { reported were due to errors } \\
\text { in communication. Majority } \\
\text { of hospital staff believe that } \\
\text { nurses have the primary } \\
\text { responsibility for preventing } \\
\text { patient safety accidents. } \\
\text { Creating a culture of safety } \\
\text { promotes where safety } \\
\text { activities fit. }\end{array}$ \\
\hline $\begin{array}{l}1 \\
5\end{array}$ & $\begin{array}{l}\text { Golle, L., Ciotti, D., } \\
\text { Gehrke, H., Gehrke Herr, } \\
\text { G. E., Aozane, F., } \\
\text { Schmidt, C. R., Bernat \& } \\
\text { Kolankiweics, A. C. } \\
\text { (2018). Culture of patient } \\
\text { safety in hospital private. } \\
\text { Cuidado Fundamental, } \\
\text { 10(1), 85-89. } \\
\text { http://dx.doi.org/10.9789/ } \\
\text { 2175- } \\
\text { 5361.2018.v10i1.85-89 }\end{array}$ & $\begin{array}{l}\text { Cross- } \\
\text { sectional } \\
\text { study. } 215 \\
\text { nursing } \\
\text { participant } \\
\text { s. }\end{array}$ & $\begin{array}{l}\text { Level } \\
\text { III/High } \\
\text { Quality }\end{array}$ & $\begin{array}{l}\text { Safety } \\
\text { Attitudes } \\
\text { Questionnaire. } \\
\text { Used with } \\
\text { permission. } \\
\text { Used in } \\
\text { multiple } \\
\text { primary } \\
\text { studies. } \\
\text { Cronbach's } \\
\text { alpha test } \\
0.837 \text {. }\end{array}$ & $\begin{array}{l}\text { There is distance between } \\
\text { nursing management and } \\
\text { leadership and frontline } \\
\text { staff. Experienced nurses } \\
\text { tend to develop safer } \\
\text { practices. It is critical that } \\
\text { managers analyze the } \\
\text { cultural aspects of the } \\
\text { organization. Lack or } \\
\text { resources leads to higher } \\
\text { rates of error. The } \\
\text { incorporation of a safety } \\
\text { culture is a key strategy for } \\
\text { providing excellence in care. }\end{array}$ \\
\hline $\begin{array}{l}1 \\
6\end{array}$ & $\begin{array}{l}\text { Jember, A., Hailu, M., } \\
\text { Messele, A., Demeke, T., } \\
\text { \& Hassen, M. (2018). } \\
\text { Proportion of medication } \\
\text { error reporting and } \\
\text { associated factors among } \\
\text { nurses: A cross sectional } \\
\text { study. BMC Nursing, } \\
\text { 17(1). } \\
\text { http://dx.doi.org/10.1186/ } \\
\text { s12912-018-0280-4 }\end{array}$ & $\begin{array}{l}\text { Quantitati } \\
\text { ve cross- } \\
\text { sectional } \\
\text { study. } \\
\text { ICU } \\
\text { settings. } \\
423 \\
\text { participant } \\
\text { s. }\end{array}$ & $\begin{array}{l}\text { Level } \\
\text { III/Good } \\
\text { Quality }\end{array}$ & $\begin{array}{l}\text { Self- } \\
\text { administered } \\
\text { questionnaire. }\end{array}$ & $\begin{array}{l}\text { Encouraging administrators } \\
\text { attitudes and responses to } \\
\text { medication error reporting } \\
\text { were appreciated. } 70.8 \% \text { of } \\
\text { medication errors were made } \\
\text { by married individuals } \\
\text { compared to non-married } \\
\text { individuals. The medication } \\
\text { error experience, having mad } \\
\text { a past medication error, sex } \\
\text { of the participant and marital } \\
\text { status were significantly } \\
\text { associated with medication } \\
\text { errors. }\end{array}$ \\
\hline
\end{tabular}




\begin{tabular}{|c|c|c|c|c|c|}
\hline $\begin{array}{l}1 \\
7\end{array}$ & $\begin{array}{l}\text { Costa Fermo, V., Ranunz, } \\
\text { V., Martins de Rosa, L., } \\
\text { \& Mendes Marinho, M. } \\
\text { (2018). Patient safety } \\
\text { culture in a bone marrow } \\
\text { transplantation unit. } \\
\text { Revista Brasileira de } \\
\text { Ernfermagem, 68(6), 827- } \\
\text { 834. }\end{array}$ & $\begin{array}{l}\text { Quantitati } \\
\text { ve cross- } \\
\text { sectional } \\
\text { study. } \\
\text { Analyzed } \\
33 \\
\text { profession } \\
\text { al studies. }\end{array}$ & $\begin{array}{l}\text { Level } \\
\text { III/Good } \\
\text { Quality }\end{array}$ & $\begin{array}{l}\text { Safety } \\
\text { Attitudes } \\
\text { Questionnaire. } \\
\text { Used with } \\
\text { permission. } \\
\text { Used in } \\
\text { multiple } \\
\text { primary } \\
\text { studies. }\end{array}$ & $\begin{array}{l}\text { The health institution should } \\
\text { develop protection measures } \\
\text { to prevent mistakes. A } \\
\text { common objective should be } \\
\text { determined. Leadership must } \\
\text { be leveraged. Involve the } \\
\text { frontline staff. Do not } \\
\text { generate guilt so that events } \\
\text { can be evaluated to } \\
\text { determine how faults go past } \\
\text { the defense mechanisms in } \\
\text { place. }\end{array}$ \\
\hline $\begin{array}{l}1 \\
8\end{array}$ & $\begin{array}{l}\text { Hahtala, M., Tolvanen, } \\
\text { A., Mauno, S., \& feldt, T. } \\
\text { (2015). The associations } \\
\text { between ethical } \\
\text { organizational culture, } \\
\text { burnout, and engagement: } \\
\text { A multilevel study. } \\
\text { Journal of Business and } \\
\text { Psychology, 30(2), 399- } \\
\text { 414. } \\
\text { DOI:10.1007/s10869- } \\
\text { 014-9369-2 }\end{array}$ & $\begin{array}{l}\text { Cross- } \\
\text { sectional } \\
\text { study. } \\
3,402 \\
\text { participant } \\
\text { s. }\end{array}$ & $\begin{array}{l}\text { Level } \\
\text { III/Good } \\
\text { Quality }\end{array}$ & $\begin{array}{l}\text { Questionnaire. } \\
\text { Likert Scale. } \\
\text { Self- } \\
\text { administered, } \\
\text { anonymous. }\end{array}$ & $\begin{array}{l}\text { Ethical organizational } \\
\text { culture is a socially } \\
\text { constructed phenomenon } \\
\text { that differs between work } \\
\text { units. Culture is associated } \\
\text { with occupational well-being } \\
\text { at both the individual and } \\
\text { work-unit levels. }\end{array}$ \\
\hline
\end{tabular}




\section{Appendix C}

Quality of Evidence

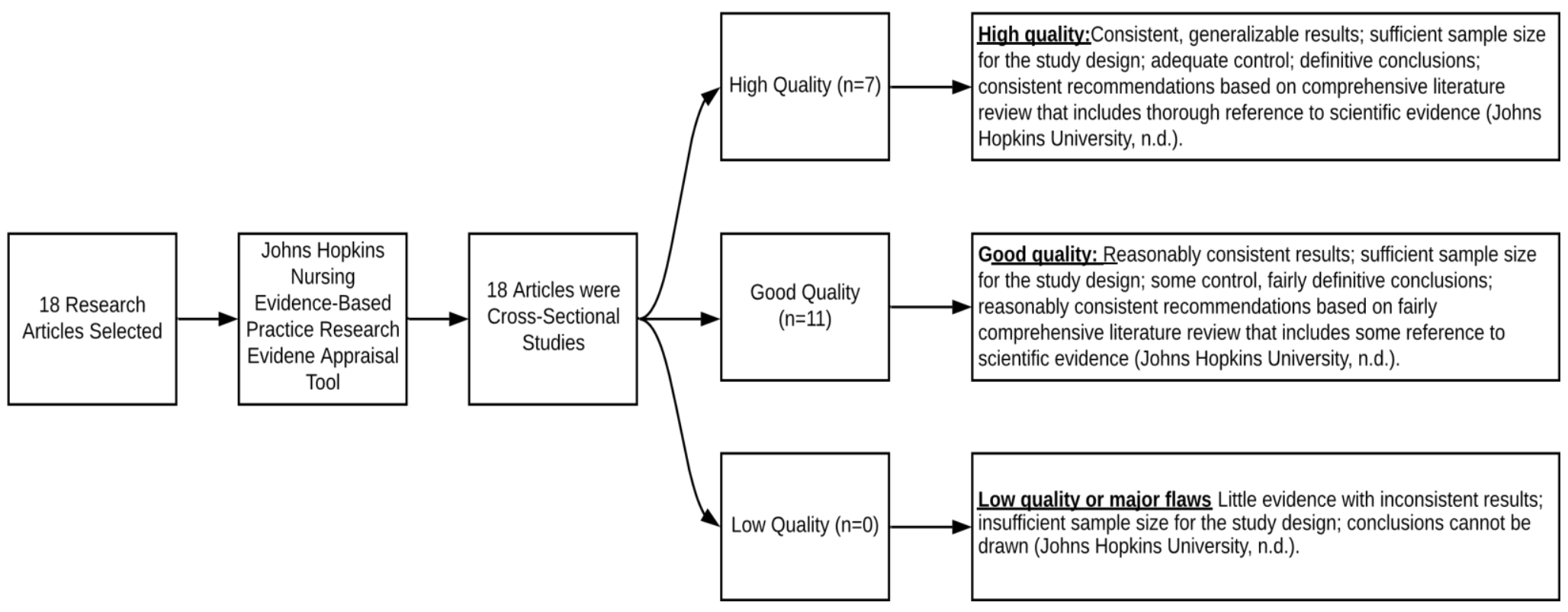


Appendix D

Themes Gathered from the Evidence

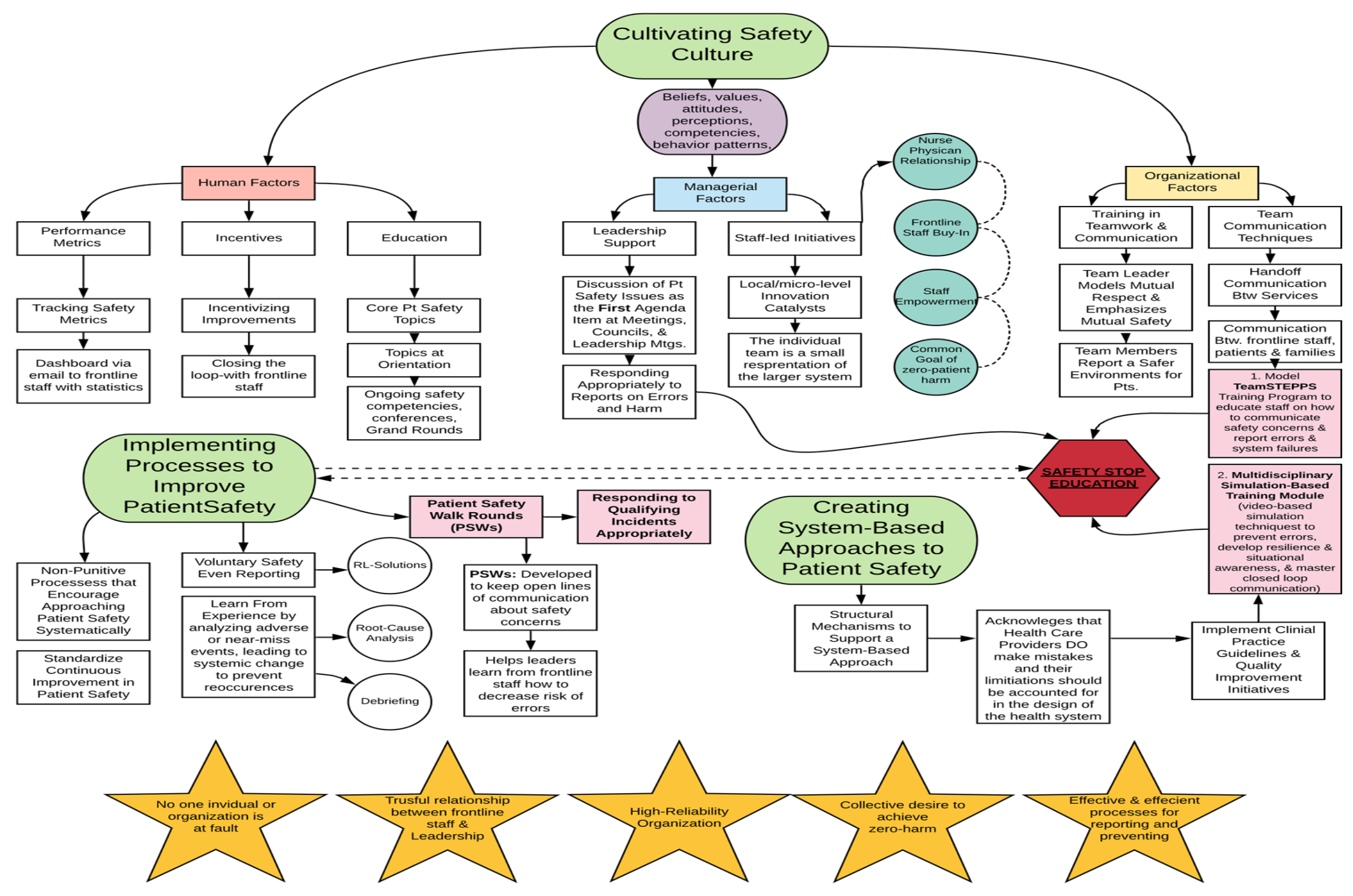




\section{Appendix E}

Practice Recommendations from Literature Review:

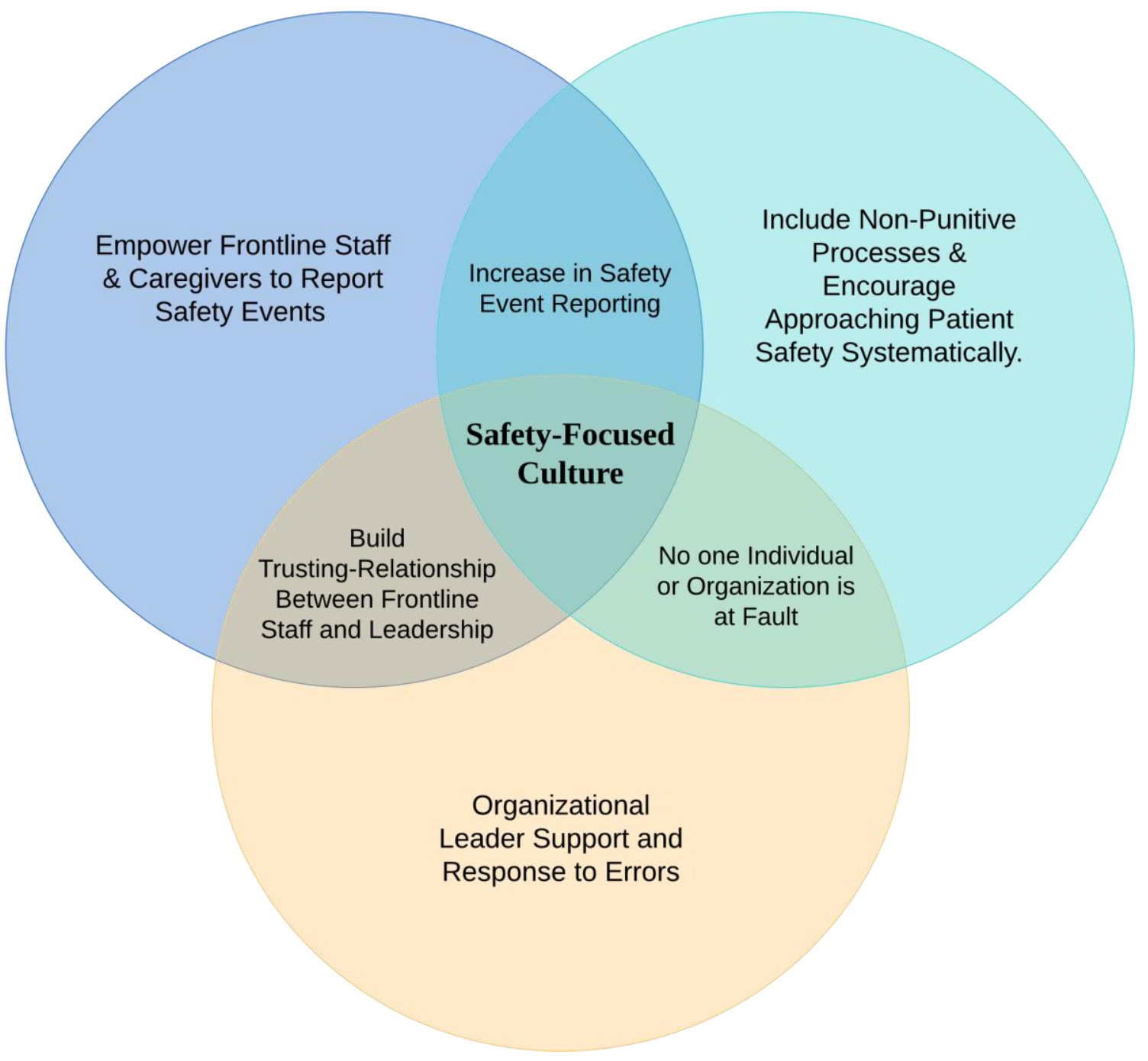




\section{Appendix F}

\begin{tabular}{|c|c|c|}
\hline \multicolumn{3}{|c|}{ PROJECT SWOT ANALYSIS } \\
\hline & Helpful (to achieving the objective) & Harmful (to achieving the objective) \\
\hline \multirow[b]{2}{*}{ 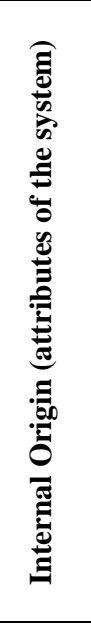 } & Strengths & Weaknesses \\
\hline & $\begin{array}{l}\text { 1. Organization operates within a large healthcare } \\
\text { system that supports cultivating a change in } \\
\text { culture. } \\
\text { 2. Organizational leaders support the project and } \\
\text { encourage sustainability. } \\
\text { 3. Emergency Department leadership supports } \\
\text { the project. } \\
\text { 4. Large patient population. }\end{array}$ & $\begin{array}{l}\text { 1. There is currently an interim Director of the } \\
\text { Emergency Department. New Director begins at } \\
\text { time of training. } \\
\text { 2. Large budget cuts due to COVID19 } \\
\text { 2. The nurse manager role is vacant. } \\
\text { 3. The assistant nurse manager role is vacant. } \\
\text { 4. The nursing staff is unionized. } \\
\text { 5. There is currently a hand-off communication } \\
\text { pilot occurring in the emergency department. } \\
\text { 6. Administrator on-call may need to drive to the } \\
\text { organization during off-hours creating decreased } \\
\text { job satisfaction. } \\
\text { 7. Increased workload for leadership responding to } \\
\text { Safety STOP. } \\
\text { 8. House-manager workload/responsibilities and } \\
\text { participation in training. }\end{array}$ \\
\hline \multirow[b]{2}{*}{ 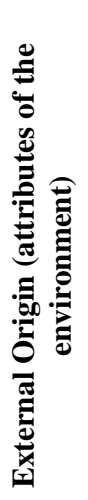 } & Opportunities & Threats \\
\hline & $\begin{array}{l}\text { 1. Can decrease the long-term cost to the U.S. } \\
\text { healthcare system. } \\
\text { 2. Can increase reimbursement rates from } \\
\text { Medicare and Medicaid } \\
\text { 3. Project is cost-effective. } \\
\text { 4. Can increase levels of patient satisfaction and } \\
\text { prevent harm. } \\
\text { 5. Can improve the culture of safety and staff } \\
\text { engagement survey results, which can lead to an } \\
\text { improvement in hospitals' five-star rating and } \\
\text { quality of care. }\end{array}$ & $\begin{array}{l}\text { 1. The United States is facing the COVID-19 } \\
\text { pandemic. This can lead to reduced staffing, staff } \\
\text { burnout, reduced resources, unpredictable number } \\
\text { of emergency department visits. } \\
\text { 2. COVID-19 may cause travel restrictions for the } \\
\text { project manager. } \\
\text { 3. COVID-19 can affect changes in laws, } \\
\text { regulations, and may cause a shift if } \\
\text { organizational focus away from the project. }\end{array}$ \\
\hline
\end{tabular}




\section{Appendix G}

\section{Northern Light.}

\section{Eastern Maine Medical Center}

Stop the Line for Zero Harm
Safety STOP
Empowering Everyone to Speok-on, Every Time
STOP

\section{Safety STOP Pilot Project}

(October 5 - October 30, 2020)

Safety STOP is a valid and reliable tool used to effectively and efficiently respond to potential threats to patient and caregiver safety. A Safety STOP will activate a leader team to rapidly respond to an event that has caused or has the potential to cause harm.

Pilot Purpose: Test the Safety STOP program before implementing it hospitalwide. Findings from the pilot will be used to make necessary changes and countermeasures to ensure a sustainable Safety STOP program at NLEMMC.

This pilot will test the following:

1. Education of caregivers

2. Activation of Safety STOP

3. Response to Safety STOP

4. Hand-off of event at daily NLEMMC organization safety briefing

Setting: NLEMMC Emergency Department

Participants: Physicians, nurse practitioners, physician assistants, nurses, certified nursing assistants, and psychiatric technicians employed in the ED (caregivers).

\section{Pilot Metrics that will be Measured:}

1). The rate (percentage) of all safety events reported in the $\mathrm{ED}$.

2). Caregiver Perceptions of hospital management's response to safety events (5point, Likert scale pre and post survey).

3). Total number of safety events reported via Safety STOP activation.

4). Total number of safety events reported via RL Solutions.

Pilot Goals:

1). Increase the total number of safety and harm events reported by ED caregivers.

2). Improve caregiver perceptions of hospital management's response to safety events.

3). Identify areas for improvement before hospital-wide implementation of Safety STOP program.

\section{Long-term Safety STOP Goals:}

1). Empower everyone at NLEMMC to speak up and "Stop the Line" every time to achieve the common goal of zero harm.

2). Reduce the opportunity for human error and capture errors before they reach the patient and caregiver.

3). Improve the safety and quality of care patients receive at NLEMMC.

4). Cultivate a culture of safety that supports a "Just Culture" and non-punitive processes that encourage approaching patient safety systematically.

5). Improve the relationship between caregivers and hospital leadership.

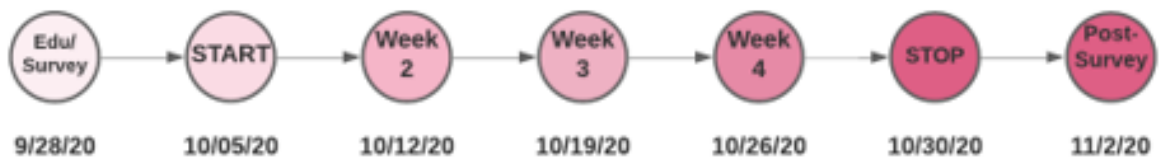




\section{Appendix $\mathrm{H}$}

Northern Light

Health.

\section{Safety STOP}

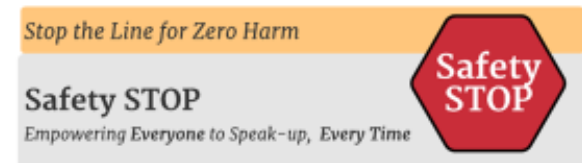

\section{Purpose}

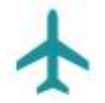

Safety STOP Pilot

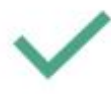

Timeline

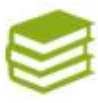

Pilot education for caregivers

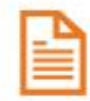

Cohesive terminology that aligns with NLEMMC
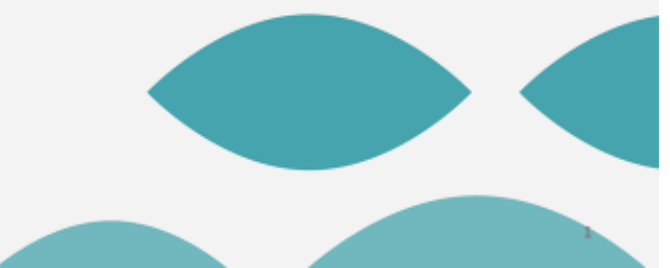

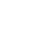




\section{Pilot Summary}

- Caregiver will activate Safety STOP by calling operator (Voicera or telephone) by dialing zero and request a safety stop. Operator will page Safety STOP responders.

- 0700-1700 (M-F)

- House Manager, Safety Facilitator, AOC

- $1700-0700$ (M-F) \& Weekends

- House Manager, triages situation and requests $\mathrm{AOC}$ if event qualifies (National Quality Form-Serious Reportable Events)

Northern Light Health.
- Checklist/Documentation Form

- Safety Facilitator 0700-1700 (M-F)

- House Manager 1700-0700 (M-F) and weekends

- RL Solution Event Report

- Completed by Caregiver

- Checklist uploaded by Safety Facilitator (Day) House-manager (night and weekends)

- Hand-off

- Daily Safety Debriefing

- $A O C$ shares safety event to group

\section{Pilot}

- Four (4) weeks

- Oct 5- Oct 30

- Emergency Department
- Caregivers Nurses, physicians, CNAs, PAs, NPs

- Online-Education

- Flowsheet/list

- Leadership: AOCs, Risk Management, Patient Safety/Performance Improvement

- Operator

- House-managers: Spreadsheet List 


\section{Pilot Goals}

- Test and identify areas for improvement before hospital-wide implementation

- Process, tools/forms, communication, follow-up to caregivers

- Improve caregiver perceptions of hospital leader's response to Safety Events

- Increase the total number of safety events reported by caregivers

- Sustainability

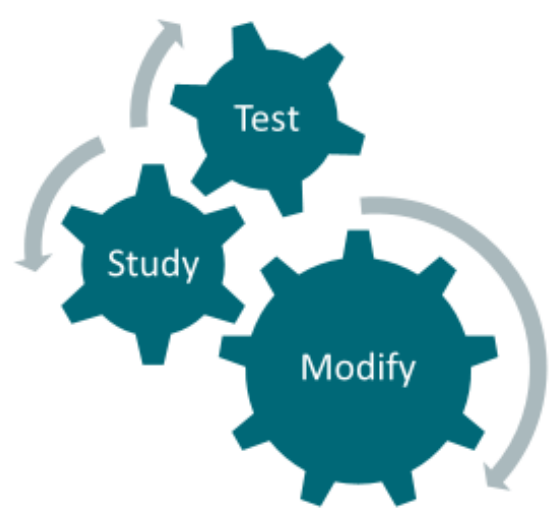

\section{Timeline}

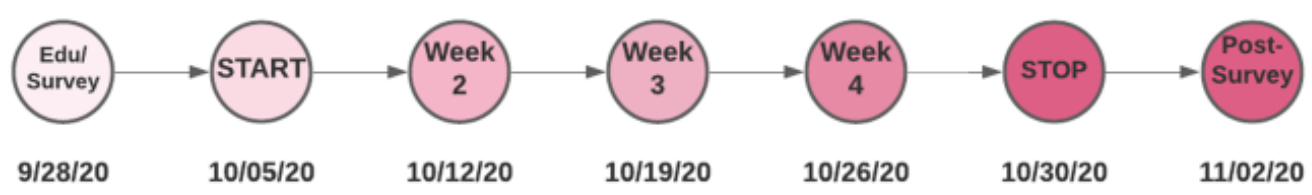




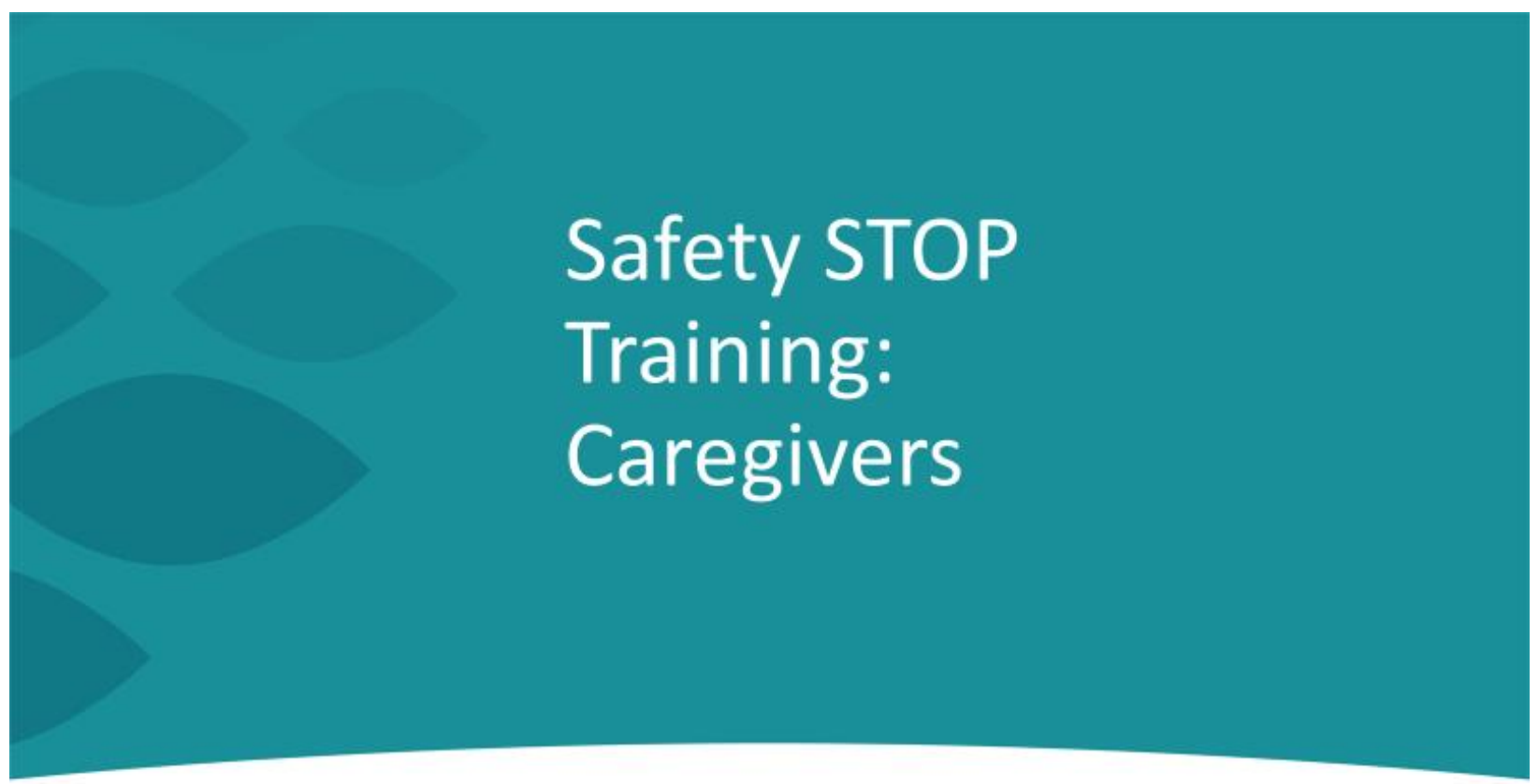

\section{Safety STOP Training: Caregiver}

- Important: You must complete this required learning course

- Safety STOP Training is comprised of one video and one PowerPoint presentation

- There is a quiz at the completion of this training. A score of $\mathbf{1 0 0 \%}$ must be achieved to demonstrate competency.

- Learning Objectives:

- Describe what a safety STOP is why it is being implemented at NLEMMC

- Explain why reporting safety events is essential to learn and prevent harm

- Outline how and when to activate a Safety STOP

- Articulate your role and responsibility when activating a Safety STOP 


\section{Safety STOP Training: Caregiver}

\section{Stop the Line for Zero Harm}

Safety STOP

Empowering Everyone to Speak-up, Every Time

Safety STOP:

- Empowers every employee at NLEMMC to "stop the line" when a safety or harm event is recognized

- Is a timely response from leadership to serious safety events to patient and caregiver safety

- Activation of a leadership team to rapidly respond to an event that has or has the potential to cause serious harm

- Is a non-punitive process that encourages approaching patient safety systematically

\section{WHY should we call a Safety STOP?}

- To provided immediate and comprehensive response to serious safety events

- To ensure appropriate care and attention is given to the patient family, family, caregivers and providers

- Allows NLEMMC to learn from experience by analyzing serious safety events and making systemic changes to STOP prevent reoccurrences 


\section{WHEN to call a Safety STOP}

- Any unsafe circumstance that did or could result in harm to a patient or caregiver

- Is considered a "Never Event" (see next slide)

- Delays in treatment that did or could result in serious harm or death

- Equipment or facility failure that requires escalation

- Sterile Processing Failure

- Any event that impacts 3 or more patients or caregivers

- Threat of harm to patient or caregiver

http://www.qualityforum.org/Topics/ SREs/List of SREs.aspx

NATIONAL

QUALITY FORUM 


\section{If Patient is Unstable}

If your patient is UNSTABLE:

- Follow hospital policy and activate code, as necessary.

- See the EMMC Emergency Conditions and Basic Staff Response

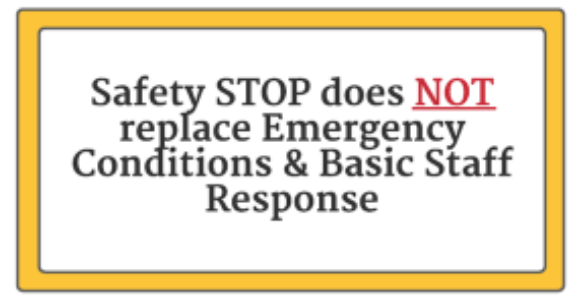

Northern Light Health.
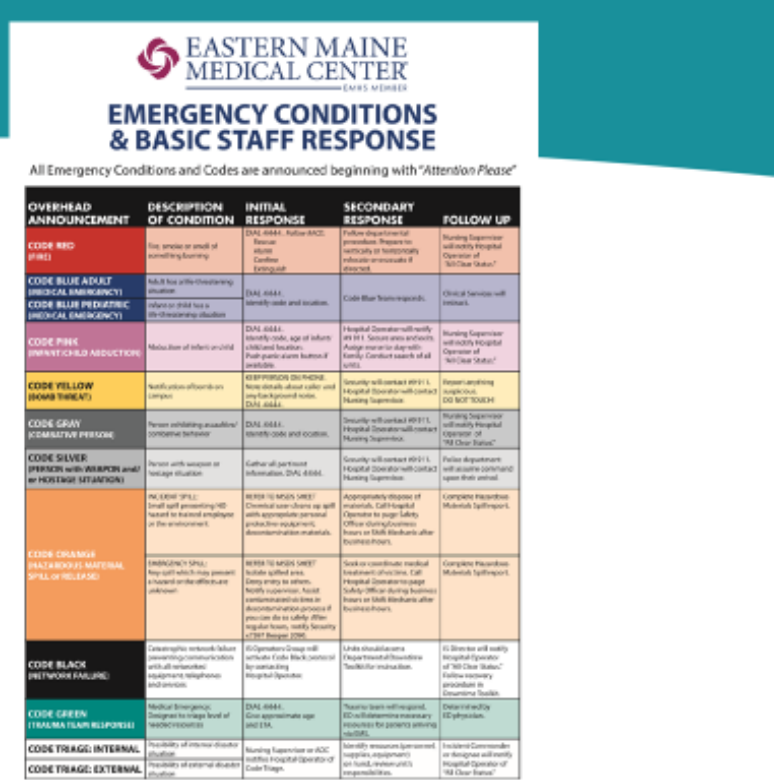

DIAL 4444 FOR ALL EMERGENCIES

\section{If patient is STABLE}

\section{PATIENT CONDITION IS STABLE:}

\section{CHECK IF ONE OF THE SIGNIFICANT} EVENTS HAS OCCURED:

-NQF Never 29 Event

Delay in treatment that resulted in serious harm

Equipment of facility failure that requires increased

physician ordered interventions or escalation to a highe

level of care

Sterile Processing failure that reaches the patient

-Any unsafe circumstance that could result in imminent

harm
IF IT APPEARS A SIGNIFICANT EVENT HAS OCCURED:

Dial Operator to initiate a Safety STOP Cal

Notify on-duty Charge Nurse/Supervisor immediately

All involved staff must remain in the area until

dismmissed by the response team

Complete a RL event report 


\section{Activating a Safety STOP}

1. When you recognize a safety or harm event has occurred

2. Ensure the patient is safe and stable

Use the unit telephone or voicera to call the operator and ask for a Safety STOP. Be ready to provide the room \# and unit name.

3. If the incident qualifies, call a Safety STOP.

\section{What happens when you call a Safety STOP?}

1. Three (3) representatives from leadership will arrive to the scene within ten minutes of the notification

2. A safety checklist form will be completed by the Safety Facilitator

3. Patient and caregiver safety and wellbeing will be assessed

4. Items will be sequestered, if necessary

5. RL safety report will be completed by caregiver

6. Immediate countermeasures will be put in place to prevent future harm 


\section{After the Safety STOP}

1. The Safety Facilitator will upload the completed Safety STOP checklist into the $\mathrm{RL}$ report created by the caregiver

2. The event will be discussed at hospital's next daily safety debriefing

3. Leadership will follow-up with the unit or staff after the debriefing to thank team for participation and update on plan of action to prevent another occurrence

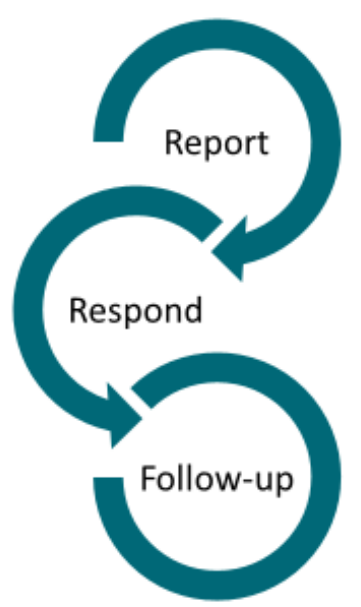

\section{Over Night \& Weekends}

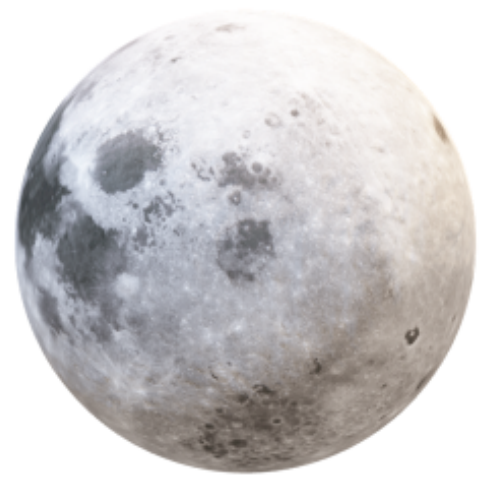

Northern Light Health.
- From the hours of $\mathbf{1 7 0 0}$ to $\mathbf{0 7 0 0}$ and Weekends, one person will arrive to scene (house manager)

- The house manager will assess the event and determine if the Administrator on Call should come to scene. 


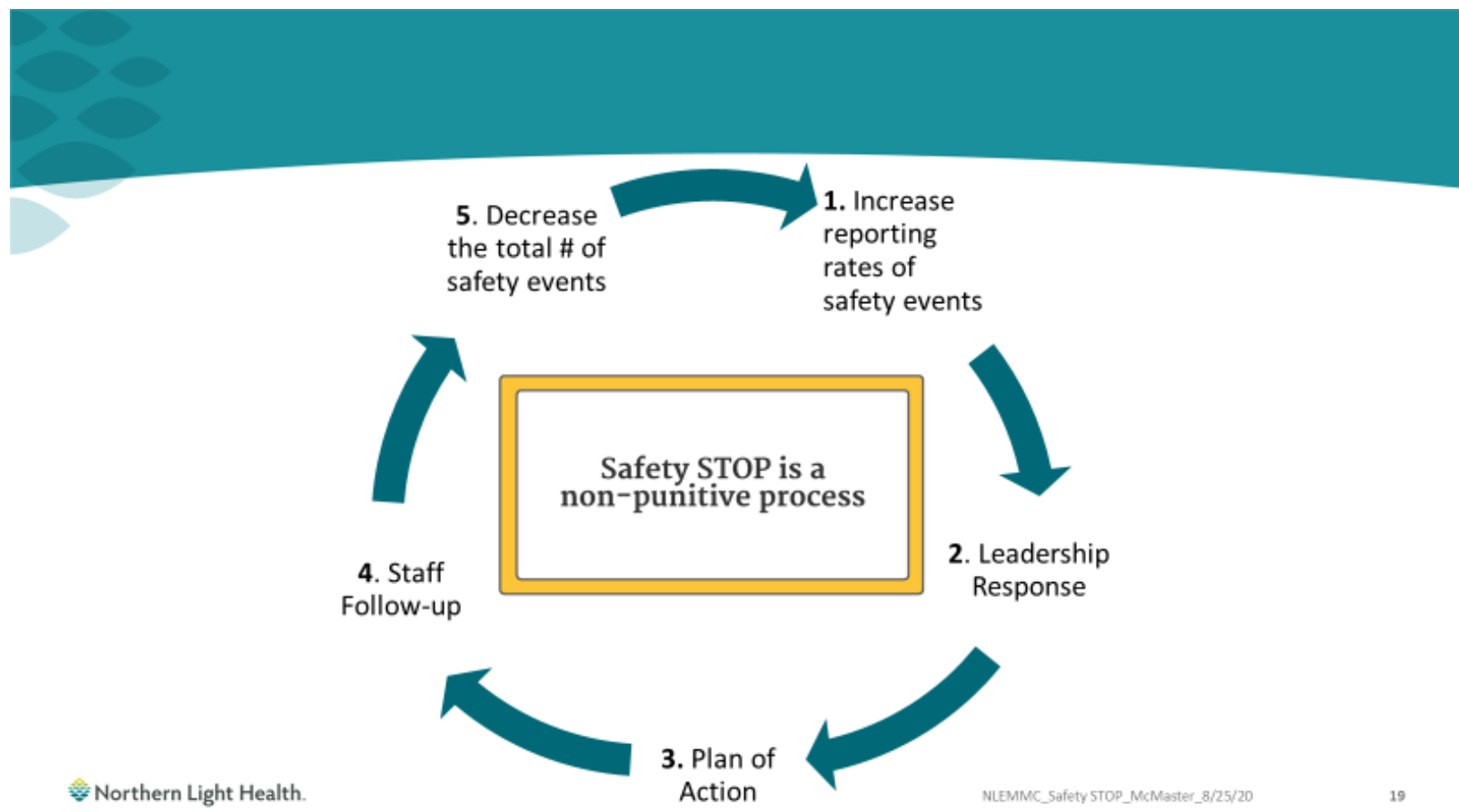

\begin{tabular}{|c|c|}
\hline & Task Description \\
\hline 1 & $\begin{array}{l}\text { Ensure patient is safe/stable. } \\
\text { Ensure appropriate crnical personnel are called to stablize the patient as needed (i.e. } \\
\text { provider, RRT, Code). }\end{array}$ \\
\hline 2 & Call Safety STOP \\
\hline 3 & Notify Charge Nurse, Manager, Supervisor, or Lead that 'Safety STOP' has been called. \\
\hline 4 & Sequester appropriate equipment, medication vials, packaging, etc. \\
\hline 5 & Describe the event to the House Supervisor when they arrive. \\
\hline 6 & $\begin{array}{l}\text { Your wellbeing is important during this process. The Safety STOP response team will be } \\
\text { checking in with you to see how you are doing. During this process, please identify and }\end{array}$ \\
\hline 7 & Stay on the scene (unit) until excused by Safety STOP Response Team. \\
\hline 8 & Participate in interview. \\
\hline 9 & Important: Complete RL Safety Event report. Notify AOC/Responder of report number. \\
\hline 10 & Attend the on-unit debrief huddle. \\
\hline
\end{tabular}




\section{Thank you!}

- By activating a Safety STOP, you are contributing to keeping our patients safe from harm

- You are helping NLEMMC approach patient safety systematically

YOU ARE HELPING OUR ORGANIZATION ACHIEVE ZERO PATIENT HARM

\section{Quiz Questions}

1. Safety STOP is a timely response from leadership to serious safety events to patient and caregiver safety

a) True-Correct

b) False

2. Who can call a Safety STOP?
a) Any caregiver or staff member - Correct
b) Only physicians
c) Only charge nurse

3. Safety STOP will improve patient and caregiver safety?
a) True - Correct
b) False

4. I have read the presentation on Safety STOP and understand how to activate Safety STOP.
1. True - Correct
2. False 


\section{Appendix $\mathrm{H}-2$}

Northern Light

Eastern Maine Medical Center

Stop the Line for Zero Harm

Safety STOP

Empowering Everyone to Speak-up, Every Time

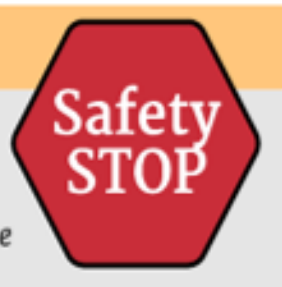

Safety STOP' Flow Sheet: ACTIVATOR

Activator: Any NLEMMC staff member who recognized the safety event.

\section{PATIENT STICKER}

\begin{tabular}{|c|c|c|}
\hline \multicolumn{3}{|c|}{ Location of Event: } \\
\hline \multicolumn{3}{|c|}{ Date of Event: } \\
\hline \multicolumn{3}{|c|}{ Time of Event: } \\
\hline \multicolumn{3}{|c|}{ Emplovee who Activated Safety STOP: } \\
\hline \multicolumn{3}{|c|}{ Name of Supervisor/Charge Nurse: } \\
\hline & \multicolumn{2}{|l|}{ Task Description } \\
\hline 1 & $\begin{array}{l}\text { Ensure patient is safe/stable. } \\
\text { Ensure appropriate clinical personnel are ca }\end{array}$ & alled to stabilize the patient as needed (i.e. provider, RRT, Code). \\
\hline 2 & Call Safety STOP & \\
\hline 3 & Notify charge nurse, manager, supervisor, & or lead that 'Safety STOP' has been called. \\
\hline 4 & Sequester appropriate equipment, medicatic & on vials, packaging, etc. \\
\hline 5 & Describe the event to the safety facilitator $/ \mathrm{h}$ & nouse manager when they arrive. \\
\hline 6 & $\begin{array}{l}\text { Your wellbeing is important during this pro } \\
\text { to see how you are doing. During this proce } \\
\text { emotionally safety to continue patient care. }\end{array}$ & $\begin{array}{l}\text { Thess. The Safety STOP response team will be checking in with you } \\
\text { ess, please identify and verbalize if you are physically, mentally, and }\end{array}$ \\
\hline 7 & Stay on the scene (unit) until excused by sa & fety facilitator/house manager. \\
\hline 8 & Participate in interview. & \\
\hline 9 & Important: Complete RL Safety Event repo & rt. Notify safety facilitator/house manager of report number. \\
\hline 10 & Attend the on-unit debrief huddle. & \\
\hline
\end{tabular}

Comments/Feedback to improve form or Safety STOP process:

CONFIDEVTIAL RECDADS: DO NOT RELEASE WITHOUT A COURT OADER This record was created and is maintained in cornection with EMMC's activities designed to maintain and improve qualty of care, reduce martidty and mortality, and/or establich and enforce appropriate standards of professional qualfication.

competence, conduct or performance. The information contained in this record is confidertial, and may be priviloged, under various state and federal laws and regulationa, induding 24 M.R.S. Chapter 21, 32 M.R.SA. 93296 , Maine Fule of Evidence 502, and Maine Rule of Chal Procedure 26. You are hereby natified that any unautharized use, disclosure, cappine, or distribution of any kind is strictly prohibited and may be unlawful. If you are nat the intended recipient of this record, please notify EMMC's affice/s) of dinical risk and quality improvement, and then delete ar destroy all dectronic and hard copies of this record 


\section{Appendix I}

\begin{tabular}{|c|c|}
\hline \multicolumn{2}{|c|}{\begin{tabular}{|c|} 
National Quality Forum Serious Reportable Events in Healthcare \\
\end{tabular}} \\
\hline \multirow{5}{*}{$\begin{array}{l}\text { Surgical or } \\
\text { Invasive } \\
\text { Procedure } \\
\text { Events }\end{array}$} & -Surgery or other invasive procedure performed on the wrong site \\
\hline & -Surgery or other invasive procedure performed on the wrong patient \\
\hline & -Wrong surgical site or other invasive procedure performed on a patient \\
\hline & -Unintended retention of a foreign object in a patient after surgery or other invasive procedure \\
\hline & -Intraoperative or immediately postoperative/post-procedure death in an ASA Class 1 patient \\
\hline \multirow{4}{*}{$\begin{array}{l}\text { Product or } \\
\text { Device Events }\end{array}$} & Patient death or serious injury associated with: \\
\hline & -The use of contaminated drugs, devices, or biologics provided by the healthcare setting \\
\hline & - The use or function of a device in patient care, which the device is used or functions other than as intended \\
\hline & -Intravascular air embolism that occurs while being cared for in a healthcare setting. \\
\hline \multirow{3}{*}{$\begin{array}{l}\text { Patient } \\
\text { Protection } \\
\text { Events }\end{array}$} & $\begin{array}{l}\text {-Discharge or release of a patient/resident of any age, who is unable to make decisions, to other than an authorized } \\
\text { person. }\end{array}$ \\
\hline & -Patient death or serious injury associated with patient elopement (disappearance) \\
\hline & $\begin{array}{l}\text {-Patient suicide, attempted suicide, or self-harm that results in a serious injury, while being cared for in a healthcare } \\
\text { setting }\end{array}$ \\
\hline \multirow{9}{*}{$\begin{array}{l}\text { Care } \\
\text { Management } \\
\text { Events }\end{array}$} & Patient death or serious injury associated with, or resulting from: \\
\hline & $\begin{array}{l}\text {-A medication error (e.g., errors involving the wrong drug, wrong dose, wrong patient, wrong time, wrong } \\
\text { rate, wrong preparation, or wrong route of administration) }\end{array}$ \\
\hline & -Unsafe medication of blood products \\
\hline & -The irretrievable loss of an irreplaceable biological specimen \\
\hline & -Failure to follow up or communicate laboratory, pathology, or radiology test results \\
\hline & OR \\
\hline & $\begin{array}{l}\text {-Maternal death or serious injury associated with labor and delivery in a low-risk pregnancy while being cared for in a } \\
\text { healthcare setting }\end{array}$ \\
\hline & -Death or serious injury of a neonate associated with labor and delivery in a low-risk pregnancy \\
\hline & -Artificial insemination with the wrong donor sperm or wrong egg \\
\hline \multirow{6}{*}{$\begin{array}{l}\text { Environmental } \\
\text { Events }\end{array}$} & Patient death or serious injury associated with: \\
\hline & -An electric shock in the course of a patient care process in the healthcare setting \\
\hline & -A burn incurred from any source in the course of a patient care process in a healthcare setting \\
\hline & - The use of physical restraints or bedrails while being cared for in a healthcare setting \\
\hline & OR \\
\hline & $\begin{array}{l}\text {-Any incident in which systems designated for oxygen or other gas to be delivered to a patient contains no gas, the } \\
\text { wrong gas, or are contaminated by toxic substances }\end{array}$ \\
\hline $\begin{array}{l}\text { Radiologic } \\
\text { Events }\end{array}$ & -Death or serious injury of a patient or staff associated with the introduction of a metallic object in the MRI area \\
\hline \multirow[t]{4}{*}{$\begin{array}{l}\text { Potential } \\
\text { Criminal Events }\end{array}$} & $\begin{array}{l}\text {-Any instance of care ordered by or provided by someone impersonating a physician, nurse, pharmacist, or other } \\
\text { licensed healthcare provider }\end{array}$ \\
\hline & -Abduction of a patient/resident of any age \\
\hline & -Sexual abuse/assault on a patient or staff member within or on the grounds of a healthcare setting \\
\hline & $\begin{array}{l}\text {-Death or serious injury of a patient or staff member resulting from a physical assault (i.e. battery) that occurs within or } \\
\text { on the grounds of a healthcare setting }\end{array}$ \\
\hline \multirow{5}{*}{$\begin{array}{l}\text { Other } \\
\text { (NLEMMC } \\
\text { specific) }\end{array}$} & - Any unsafe circumstance that did or could result in harm to a patient, caregiver/employee \\
\hline & -Delays in treatment that did or could result in serious harm or death \\
\hline & -Equipment or facility failure that requires escalation \\
\hline & -Sterile processing failure \\
\hline & $\begin{array}{l}\text {-Any event that impacts } 3 \text { or more patients or caregivers } \\
\text { - Threat of harm to patient or caregiver }\end{array}$ \\
\hline
\end{tabular}




\section{Appendix J}

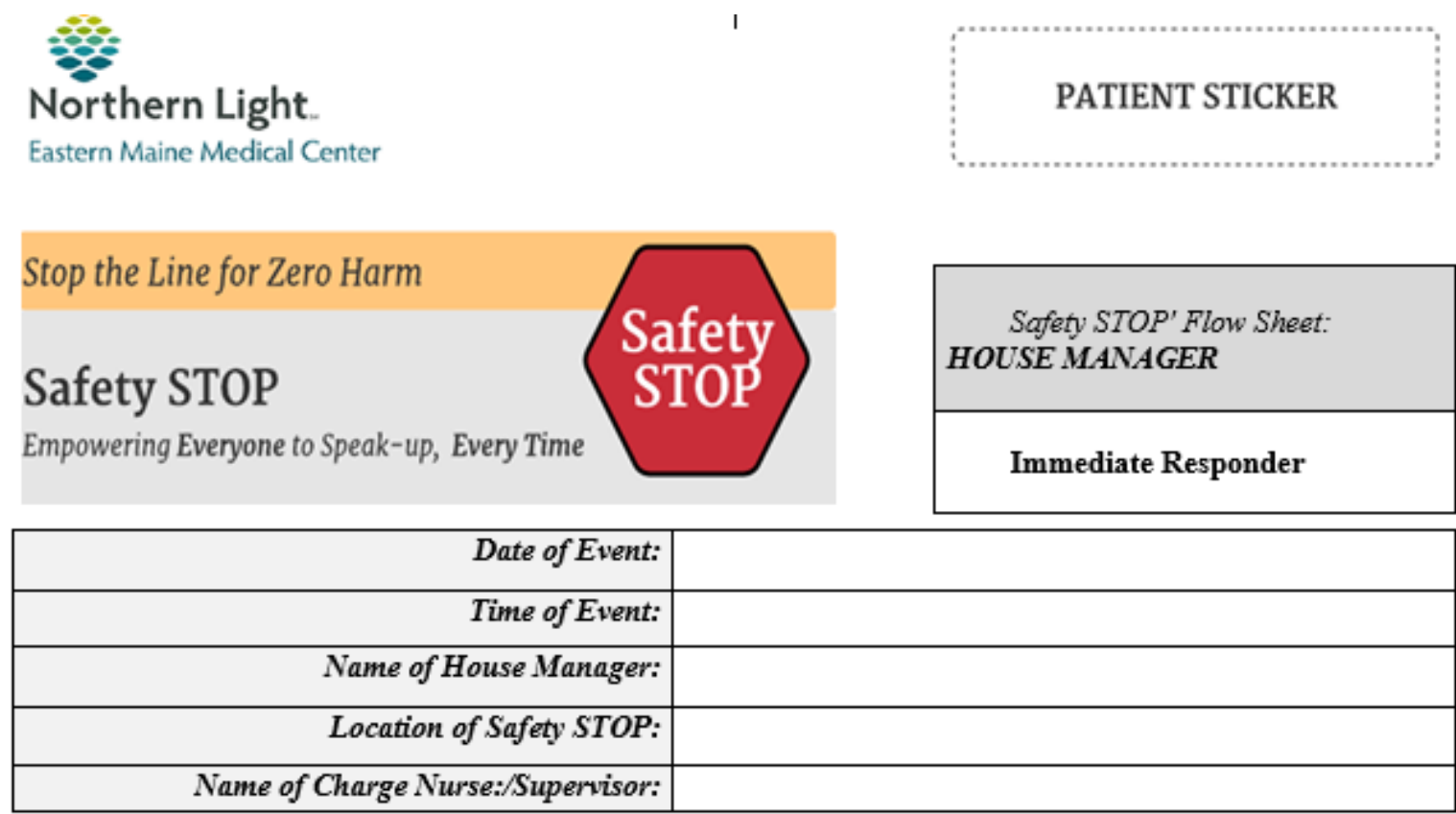

\begin{tabular}{|c|l|l|}
\hline Task \# & Task Description & Task Time \\
\hline 1 & Receive notification of 'Safety STOP' from designated communications. & \\
\hline 2 & Respond to Safety STOP location within 10 minutes. & \\
\hline 3 & Ensure patient and caregiver are safe/stable. & \\
\hline 4 & Start documentation on the Safety STOP Checklist. & $\begin{array}{l}\text { Handoff Safety STOP checklist to Safety Facilitator upon their arrival. If the Safety STOP } \\
\text { occurred between the hours of 1700 and 0700, house-manager is responsible for } \\
\text { completing the Safetv STOP check list. }\end{array}$ \\
\hline 6 & $\begin{array}{l}\text { *Between the hours of 1700 and 0700, the house-supervisor should evaluate the event to } \\
\text { determine if support from AOC is required. The AOC should be notified if the event } \\
\text { involves one of the following: } \\
\text { 1). Any event on the list of Serious Reportable Events from the National Quality Forum. } \\
\text { 2). Diversion of narcotics. } \\
\text { 3). An event that has caused serious patient harm. } \\
\text { 4). Any event requiring support for disclosure. }\end{array}$ & \\
\hline
\end{tabular}

CONFDEMTIM RECORDS: DO MOT RELESE WITHOUT A COURT ORDER This record was created and is maimained in connection whith EMMC' sactivities designed bo maistain asd improwe quaîty of care, reduce morbidity and mortality, and/or esubblish and enforce appropriase standards of probessianal qualificutios, competence, candact of performance. The information consained in this record is cosfisential, and may be privileged, under various sunte and federal laws and

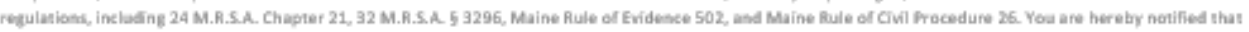

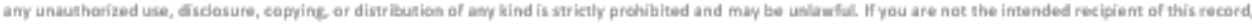

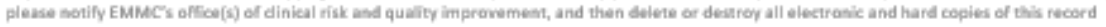




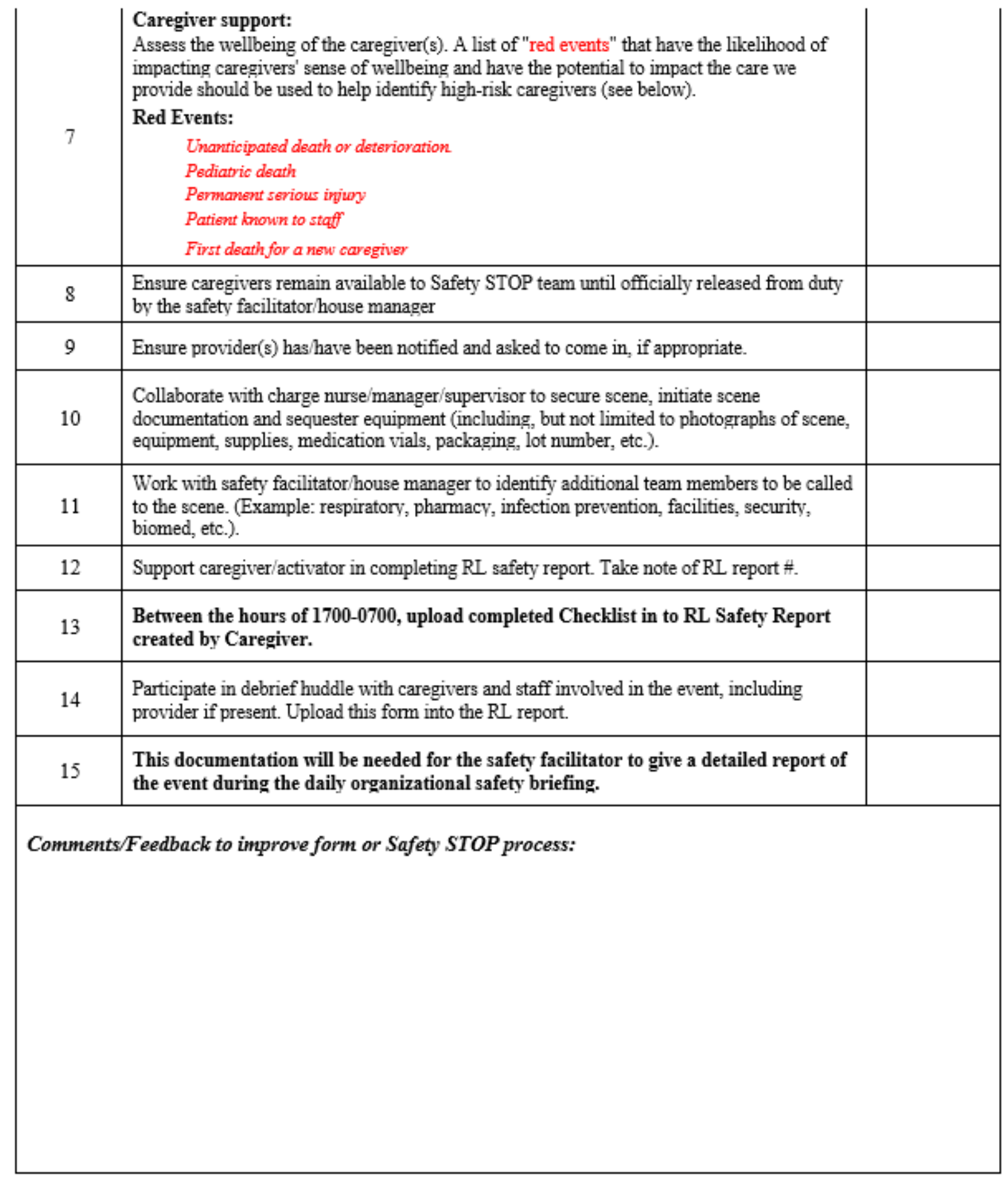

CONFEENTIM RECORDS: DO NOT RELEASE WITHOUT A COURT OKDER This recond was created and is mainained in connection with EMMC"s activities desiened so maimain and improve quality of care, reduce mortidity and mortality, and/or csublish and enforce appropriane sundards of prolessional qualification, competence, cendact of performance. The information contained in this record is cosfisentia , and may be privileged, under various sume and federal laws and

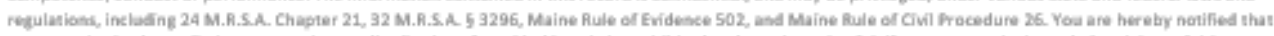
amy unauthorized use, disclasure, copying, of distributioa of asy kind is strictly prohibited and may be uvlawlal. If you are not the intended recipient of this record, please notify EMMC's offico(s) of dinical risk asd quality improvement, and then deleze of destroy all electrasic and hard copies of this record 
Appendix K

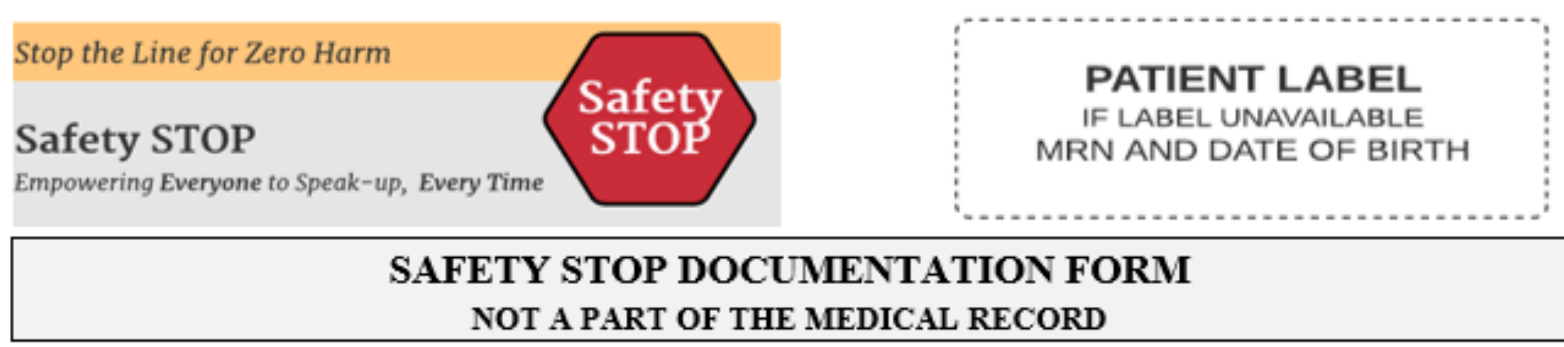

Instructions: Safety Facilitators and House Manager complete this form. Ensure this form is uploaded the RL report and brought to the daily Organization Safetv Briefing.

\begin{tabular}{|l|l|}
\hline Event Details & Event Time: \\
\hline Event Date: & Room \#:
\end{tabular}

\section{Section A: Safety Facilitator (M-F,0700-1700), House Manager (1700-0700 and Weekends)}

\section{Name \& Title:}

$\square$ Ensure Patient is safe and stable

$\square$ Assess caregiver wellbeing

$\square$ Ensure caregivers remain available until officially released from duty by safety facilitator or house manager

Event Description
Response Date \& Time:

Initiate sequestration of scene and information:

$\square$ Photographs $\square$ Supplies $\quad$ Other (Specify)

aEquipment $\quad$ Packaging
Is provider notification required?

$\square$ Yes, already notified $\quad$ No, not required aNotification Underway

Provider Name:

Event Participants:

\begin{tabular}{|l|l|l|l|}
\hline Title & Name (first \& last) & Title & Name (first \& last) \\
\hline Provider & & $\begin{array}{l}\text { Employee who } \\
\text { called Safety Stop }\end{array}$ & \\
\hline Charge RN/Lead & & Others: & \\
\hline Primary RN(s) & & Others: & \\
\hline Manager & & Others: & \\
\hline Director & & \\
\hline
\end{tabular}

CONFIDENTLAL RECORDS: DO NOT REL.EASE WITHOUT A COURT ORDER This rocond was created and is maintained in comection with EMMC's activities designed to maintain and improve quality of care, reduce morthidity and mortality, and/or establish and enforce appropriate standards of professional qualification, competenoe, oanduct or performance. The information contained in this record is coafideatial, and may be privileged, under various state and federal laws and regulations, including 24 M.R.S.A. Chapter 21, 32 M.R.S.A. 83296, Maino Rule of Evidenoe 502, and Maine Rule of Civil Procedure 26. You are hereby notified that any unauthorized use, disclosure, oppying, or distributioa of any kiad is strictly prohibited and may be unlawful. If you are not the intended recipient of this reoard, please notify EMMC's office(s) of cliaical risk and quality imaprovement, and then delete or destroy all electromic and hard copies of this rocoend. 
Section B: Ensure Caregiver Wellbeing \& Confirm RL Event Report is Created aEnsure Section $\mathbf{A}$ is complete

$\square$ Unit Manager notified? $\quad \square$ Yes $\quad$ No

$\square$ Unit Director Notified? $\quad \square$ Yes $\square$ No

$\square$ Assess caregiver wellbeing - Is caregiver okay to continue work?

$\square$ Yes $\quad$ No Action Taken:

$\square$ Ensure RL safety event report is completed

RL \#:

$\square$ During the conversations, notify caregivers that RCA may occur. Document caregiver availability for the week.

Follow-up measures to taken to protect patient and caregivers:

\begin{tabular}{|l|l|l|}
\hline Description & Assigned Leader & Date Completed \\
\hline & & \\
\hline & & \\
\hline & & \\
\hline & & \\
\hline $\begin{array}{l}\text { Are there additional areas at risk? } \square \text { Yes } \square \text { No } \\
\text { List here with names of leader(s) advised: }\end{array}$
\end{tabular}

Are there network/system risks? $\square$ Yes $\square$ No

Plans for escalation (who and when)?

Information to consider/gather for Safety STOP Huddle:

Event disclosure required? $\square$ Yes $\square$ No

Date/Time Disclosed:

Disclosed to: $\square$ Patient $\square$ Other

Disclosed By AOC: Provider: Safety Facilitator:

External reporting required? $\square$ Yes $\square$ No

Action Taken? Explain :

Action Required? Explain :

Work Order Number (If Submitted):

Section C: Response Debrief and Notification

$\square$ Debrief huddle held with house-manager, AOC, safety facilitator, and caregivers (to debrief, confirm countermeasures, and discuss next steps to be taken.

$\square$ Safety Facilitator completes and uploads Safety STOP documentation form to RL report created by caregiver. $\square$ AOC and Safety Facilitator should be prepared to discuss Safety STOP event at next day's daily NLEMMC Organization Safety Briefing

$\square$ Quality leadership delegate follow-up tasks to the appropriate individuals.

$\square$ AOC who responded to Safety STOP event should return to unit within 24 hours thanking the caregiver and unit for reporting the event and their participation. The participants should be made aware they are contributing to keeping our patient's safe from harm and helping NLEMMC approach patient safety systematically.

Additional comments and feedback:

CONFIDENT LAL RFCORDS: DO NOT RPL.EASE WITHOUT A COURT ORDFR This rocord was created and is maintained in comection with EMMC's activities designed to maintain and improve quality of care, reduce mothidity and mortality, andlor establish and enforce appropriate standards of professioual qualification, competence, conduct or performance. The information contained in this reound is confidential, and may be poivileged, under various state and federal laws and regulations, including 24 M.R. S.A. Chapter 21, 32 M.R.S.A. 83296, Maine Rule of Evidenoe $\mathbf{5 0 2}$, and Maine Rule of Civil Procedure 26. You are hereby notified that any unauthorized use, disclosure, oopying, or distribution of any kiad is strictly prohibited and may be unlawful. If you are not the intended recipient of this recard, please notify EMMC's office(s) of clinical risk and quality improvement, and then delete or destroy all electromic asd hard copies of this recoert. 
Appendix L
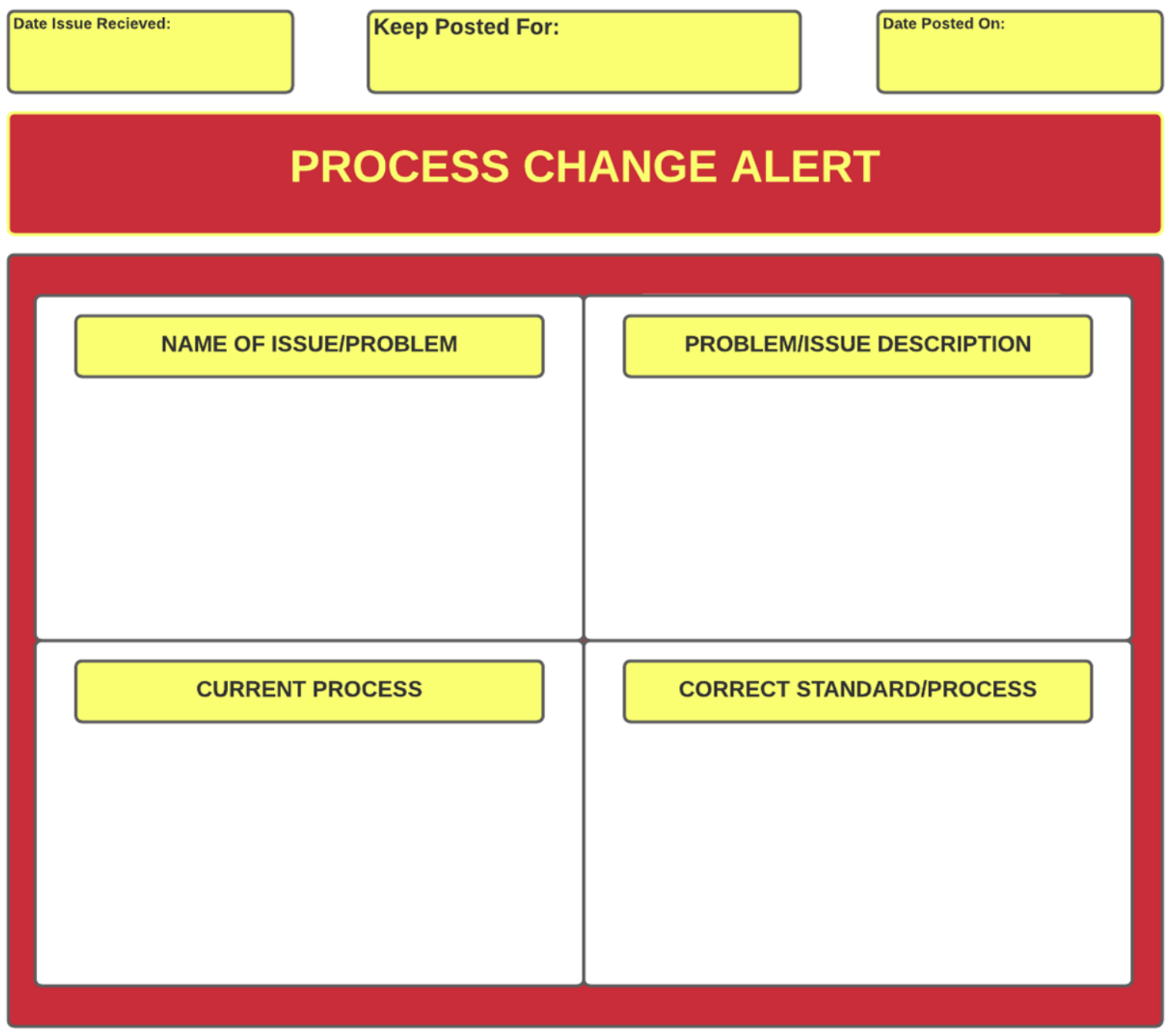

Name of Process Owner: 


\section{Appendix M}

Project Schedule

\begin{tabular}{|c|c|c|c|c|c|c|c|c|c|c|c|c|c|c|c|c|c|c|c|c|c|c|c|c|c|}
\hline \multirow{3}{*}{$\begin{array}{l}\text { Elizabeth McMaster, BSN, RN, } \\
\text { Project TIMELINE }\end{array}$} & \multicolumn{24}{|c|}{$\begin{array}{l}\text { Safety STOP: A Safety Program in a Tertiary Care Center Emergency Department: An Evidence-Based Project to Increase } \\
\text { Safety Event Reporting and Change Staff Perceptions of Hospital Management's Response to Safety Events }\end{array}$} & \\
\hline & \multicolumn{8}{|c|}{ May 11-August 22, 2020} & & \multicolumn{8}{|c|}{ September 8-Novemeber 19, 2020} & \multicolumn{8}{|c|}{ January 11-April 24, 2021} \\
\hline & \multicolumn{8}{|c|}{ NUR7801 } & & \multicolumn{8}{|c|}{ NUR7802 } & \multicolumn{8}{|c|}{ NUR7803 } \\
\hline Week & $\mathbf{1}$ & 3 & 5 & 7 & 9 & 11 & 13 & 1 & & & 3 & 5 & 7 & s & & 13 & 15 & $\mathbf{1}$ & 3 & & 7 & 9 & 11 & 1 & 15 \\
\hline Meet with Preceptor & $\mathrm{x}$ & $\mathrm{x}$ & $\mathrm{x}$ & $\mathrm{x}$ & $\mathrm{x}$ & $\mathrm{x}$ & $\mathrm{x}$ & $x$ & & $\mathrm{x}$ & $\mathrm{X}$ & $\mathrm{X}$ & $\mathrm{x}$ & 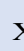 & & $\mathrm{x}$ & $\mathrm{x}$ & $\mathrm{x}$ & $\lambda$ & & $\mathrm{X}$ & $\mathrm{x}$ & $\mathrm{x}$ & $\mathrm{r}$ & $\mathrm{x}$ \\
\hline Needs Assessment & $\mathrm{x}$ & $\mathrm{x}$ & & & & & & & & & & & & & & & & & & & & & & & \\
\hline $\begin{array}{l}\text { Prepare \& Complete Project } \\
\text { Proposal }\end{array}$ & $\mathrm{x}$ & $\mathrm{x}$ & $\mathrm{x}$ & $\mathrm{X}$ & $\mathrm{x}$ & $\mathrm{x}$ & $\mathrm{x}$ & $x$ & & & & & & & & & & & & & & & & & \\
\hline Submit Final Proposal To USAH & & & & & & & & $x$ & & & & & & & & & & & & & & & & & \\
\hline $\begin{array}{l}\text { On-site at NLEMMC to assess } \\
\text { culture, obtain stakehold buy-in, } \\
\text { make specific changes, and develop } \\
\text { cohesive terminiolgy, present } \\
\text { project with leadership }\end{array}$ & & & & & & & & $x$ & & & & & & & & & & & & & & & & & \\
\hline $\begin{array}{l}\text { Submit DNP Project Application, } \\
\text { Letter of Support, and Project } \\
\text { Proposal to USAH EPRC }\end{array}$ & & & & & & & & & & & & & & & & & & & & & & & & & \\
\hline $\begin{array}{l}\text { Obtain USAH EPRC Approval \& } \\
\text { Submit Proposal to NLEMMC } \\
\text { EPRC for Project Approval }\end{array}$ & & & & & & & & & & & $\mathrm{X}$ & & & & & & & & & & & & & & \\
\hline $\begin{array}{l}\text { Participant Baseline Survey } \\
\text { Released. Education and } \\
\text { Preparedness for Safety STOP } \\
\text { Project Implementation. }\end{array}$ & & & & & & & & & & & $\mathrm{x}$ & $\mathrm{X}$ & & & & & & & & & & & & & \\
\hline Project Implementation & & & & & & & & & & & & $\mathrm{x}$ & $\mathrm{x}$ & & & & & & & & & & & & \\
\hline $\begin{array}{l}\text { Prepare Plan for Data Collection \& } \\
\text { begin analyzing project data. } \\
\text { Prepare for NUR7803. Revise } \\
\text { Proposal. Being sustainabilty } \\
\text { countermeasures. }\end{array}$ & & & & & & & & & & & & & & $x$ & & $\mathrm{X}$ & $\mathrm{x}$ & & & & & & & & \\
\hline $\begin{array}{l}\text { Ensure project sustainability, data } \\
\text { analysis, evaluation, dissemination. }\end{array}$ & & & & & & & & & & & & & & & & & & $\mathrm{X}$ & 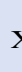 & & $\mathrm{X}$ & $\mathrm{x}$ & $\mathrm{x}$ & & $\mathrm{x}$ \\
\hline
\end{tabular}




\section{Appendix N}

Potential Project Expenses

\begin{tabular}{|c|l|}
\hline $\mathbf{1}$ & Project Expenses \\
\hline $\mathbf{2}$ & $\begin{array}{l}\text { On-call pay for non-leaders, non-salaried staff responding to } \\
\text { Safety STOP. }\end{array}$ \\
\hline $\mathbf{3}$ & $\begin{array}{l}\text { Mileage reimbursement for team members responding to safety } \\
\text { events when on-call overnight. }\end{array}$ \\
\hline $\mathbf{4}$ & $\begin{array}{l}\text { Increased workload to nursing education (i.e. uploading and } \\
\text { implementing online education modules). }\end{array}$ \\
\hline $\mathbf{5}$ & $\begin{array}{l}\text { The potential cost of staff stays over allotted shift time to } \\
\text { complete an online learning module. }\end{array}$ \\
\hline & $\begin{array}{l}\text { Cost of paper and printing of Safety STOP forms, tools, and } \\
\text { materials. }\end{array}$ \\
\hline
\end{tabular}


Metric Matrix

Appendix $\mathrm{O}$

\begin{tabular}{|c|c|c|c|c|c|c|c|c|c|c|c|c|c|c|c|c|c|c|c|c|c|c|c|}
\hline yde & tep & low & eme & ty vent prog! & rram compared t & tonosa & ct th & e of sat & safety & & nd & ns & ns of hospital manage & age & & weeks? & & & & EVALU & ATION & & \\
\hline MEASURES & & & & FEGORIES & & & TIME for $\mathrm{D}$ & ATACOLL & LEECTION & N (WEEK & & & STATISTICAL TE & & BASELINE & 60 & & & Time\#1 & & & Time\#2 & \\
\hline & OUTCOME & \begin{tabular}{|l|} 
Proocesss \\
\end{tabular} & BALANCING & FINANCIAL & CONTEXTUAL & Sustanabilutr| & Baseline & \begin{tabular}{|l|l}
1 & 2 \\
\end{tabular} & \begin{tabular}{l|l}
2 & 3 \\
\end{tabular} & 4 & 5 & Descriptive & \begin{tabular}{|c|} 
Independent \\
t-test
\end{tabular} & Proportional & Values & Week 2 & After Pilot & \begin{tabular}{c|} 
On \\
Target
\end{tabular} & At Risk & \begin{tabular}{|c|} 
In \\
Danger
\end{tabular} & \begin{tabular}{c|} 
On \\
Target
\end{tabular} & At Risk I & In Danger \\
\hline 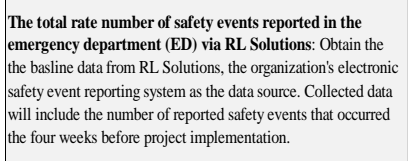 & $\mathrm{x}$ & & & $x$ & $x$ & $x$ & $\mathrm{x}$ & & $\mathrm{x}$ & & $x$ & $x$ & $\mathrm{x}$ & & 67 & $\begin{array}{c}20 \% \\
\text { improvenent } \\
\text { from baseline }\end{array}$ & \begin{tabular}{|c|}
$40 \%$ \\
improvenent \\
from baseline
\end{tabular} & $\mathrm{x}$ & & & $\mathrm{x}$ & & \\
\hline 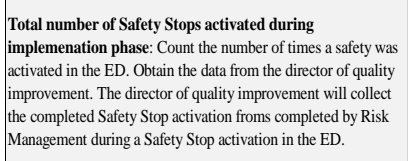 & & $\mathrm{x}$ & $\mathrm{x}$ & $x$ & $\mathrm{x}$ & $x$ & $x$ & & $\mathrm{x}$ & & $x$ & $x$ & $\mathrm{x}$ & & 0 & $\mid \begin{array}{c}10 \% \\
\text { improvenent } \\
\text { from baseline }\end{array}$ & $\left|\begin{array}{c|}20 \% \\
\text { improvement } \\
\text { from baseline }\end{array}\right|$ & $x$ & & & $\mathrm{x}$ & & \\
\hline 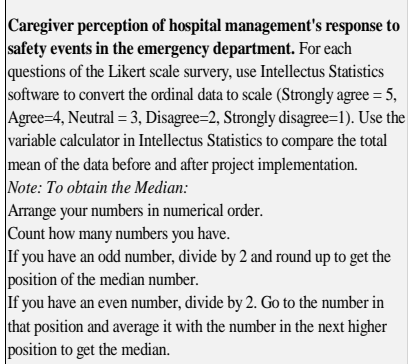 & & $\mathrm{x}$ & & & $\mathrm{x}$ & & $\mathrm{x}$ & & & & $x$ & & & $\mathrm{x}$ & $\begin{array}{c}\text { Total Man from } \\
\text { Baseline survey=y = } \\
3.48\end{array}$ & n/a & 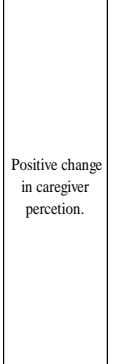 & n/a & n/a & n/a & n/a & n/a & n/a \\
\hline
\end{tabular}




\section{Appendix $\mathrm{P}$}

Safety STOP Pilot Survey (baseline and post-implementation)

\section{Safety STOP Pilot Survey: NLEMMC Emergency Department}

\section{Send to ED caregivers (Physicians, RNs, CNAs, NPs, PAs) on $9 / 28 / 20$ and 11/2/20}

1 Please indicate your Department/Unit Name:

2 If department is not listed in previous question, please enter here:

1 Please indicate your role:

2 If your role is not listed in previous questions, please enter here:

\begin{tabular}{|c|c|c|c|c|c|c|}
\hline \multicolumn{2}{|r|}{ On what level do you agree or disagree with the following statements? } & $\begin{array}{l}\text { Strongly } \\
\text { Agree }\end{array}$ & Agree & $\begin{array}{l}\text { Neutral/ Neither } \\
\text { Agree or Disagree }\end{array}$ & Disagree & $\begin{array}{l}\text { Strongly } \\
\text { Disagree }\end{array}$ \\
\hline 3 & Safety is a top priority for hospital management. & & & & & \\
\hline 4 & I know how to report a safety event, incident, or error. & & & & & \\
\hline 5 & I have reported a safety event, incident, or error in the past & & & & & \\
\hline 6 & Safety event reporting is a non-punitive process. & & & & & \\
\hline 7 & $\begin{array}{l}\text { I can openly talk about a safety event, incident, or error with fellow employees } \\
\text { or hospital management. }\end{array}$ & & & & & \\
\hline
\end{tabular}


8 Employee well-being is addressed by hospital management after a serious safety event.

9 I know what a sentinel event is.

10 When a safety event, incident, or error is reported, it is handled professionally by hospital management.

11 I receive feedback from hospital management after reporting a safety event, 11 incident, error.

12 The feedback I receive from hospital management after a safety event is timely.

${ }_{13}$ I am satisfied with the actions and feedback provided by the leadership team

when I report a safety event, incident, or error.

14 I know what actions the leadership team/hospital takes after a safety event, incident, or error is reported.

When I report a safety event, incident, or error, I am helping the hospital

15 improve systems and processes to prevent the same safety event from occurring again.

16 Reporting a safety event, incident, or error will contribute to a safer work environment for patients, visitors, and employees.

17 I believe zero patient harm is achievable.

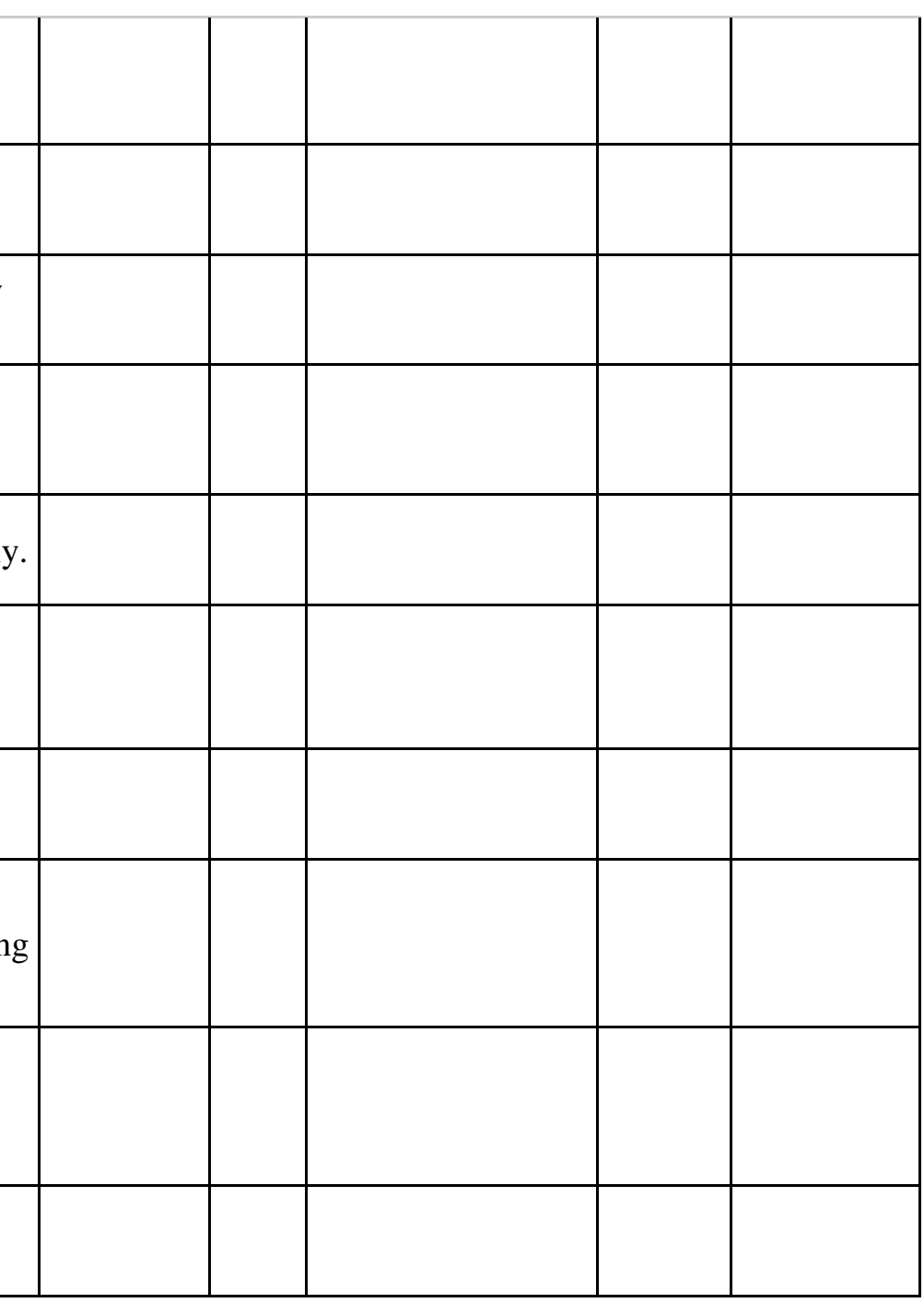




\section{Appendix Q}

Baseline (pre) and post-implementation Likert scale responses from Participants ( trongly agree=5, agree=4, Neutral=3, disagree=2, strongly disagree $=1)$ :

\begin{tabular}{|c|c|c|c|c|c|c|c|c|c|c|c|c|c|c|c|c|c|}
\hline Respondent & $\begin{array}{c}\text { Pre or Post } \\
\text { Implementation }\end{array}$ & Q1 & Q2 & Q3 & Q4 & Q5 & Q6 & Q7 & Q8 & Q9 & Q10 & Q11 & Q12 & Q13 & Q14 & Q15 & $\begin{array}{c}\text { Mean } \\
\text { Perception } \\
\text { of Staff }\end{array}$ \\
\hline 1 & Pre & 4 & 4 & 4 & 4 & 4 & 3 & 4 & 3 & 3 & 3 & 3 & 3 & 4 & 4 & 3 & 3.533333 \\
\hline 2 & Pre & 4 & 4 & 5 & 4 & 4 & 4 & 5 & 2 & 4 & 4 & 1 & 4 & 4 & 5 & 4 & 3.866667 \\
\hline 3 & Pre & 4 & 5 & 5 & 5 & 4 & 4 & 5 & 4 & 4 & 4 & 3 & 3 & 4 & 5 & 4 & 4.2 \\
\hline 4 & Pre & 2 & 4 & 4 & 3 & 3 & 3 & 4 & 3 & 2 & 3 & 3 & 2 & 3 & 3 & 3 & 3 \\
\hline 5 & Pre & 2 & 4 & 4 & 3 & 2 & 3 & 4 & 3 & 2 & 2 & 2 & 2 & 3 & 3 & 3 & 2.8 \\
\hline 6 & Pre & 3 & 4 & 4 & 2 & 4 & 2 & 4 & 2 & 2 & 2 & 3 & 3 & 4 & 3 & 3 & 3 \\
\hline 7 & Pre & 4 & 4 & 4 & 4 & 4 & 4 & 4 & 4 & 4 & 3 & 4 & 3 & 4 & 4 & 4 & 3.866667 \\
\hline 8 & Pre & 4 & 5 & 5 & 5 & 5 & 5 & 5 & 5 & 4 & 4 & 5 & 5 & 4 & 5 & 4 & 4.666667 \\
\hline 9 & Pre & 4 & 5 & 3 & 4 & 4 & 4 & 5 & 4 & 3 & 3 & 2 & 2 & 4 & 4 & 1 & 3.466667 \\
\hline 10 & Pre & 4 & 5 & 3 & 3 & 4 & 4 & 5 & 4 & 5 & 4 & 3 & 4 & 5 & 4 & 4 & 4.066667 \\
\hline 11 & Pre & 4 & 4 & 3 & 4 & 4 & 4 & 4 & 4 & 3 & 3 & 3 & 4 & 4 & 4 & 4 & 3.733333 \\
\hline 12 & Pre & 1 & 5 & 5 & 3 & 1 & 1 & 5 & 1 & 3 & 1 & 1 & 3 & 5 & 3 & 5 & 2.866667 \\
\hline 13 & Pre & 2 & 4 & 4 & 3 & 2 & 2 & 5 & 3 & 2 & 2 & 2 & 2 & 3 & 4 & 5 & 3 \\
\hline 14 & Pre & 4 & 4 & 4 & 4 & 4 & 4 & 4 & 4 & 4 & 4 & 4 & 3 & 3 & 4 & 4 & 3.866667 \\
\hline 15 & Pre & 3 & 4 & 4 & 3 & 4 & 3 & 4 & 3 & 3 & 3 & 3 & 2 & 3 & 2 & 2 & 3.066667 \\
\hline 16 & Pre & 1 & 5 & 5 & 1 & 1 & 1 & 5 & 1 & 5 & 3 & 1 & 5 & 1 & 1 & 5 & 2.733333 \\
\hline 17 & Pre & 2 & 4 & 4 & 4 & 2 & 2 & 4 & 2 & 2 & 1 & 1 & 2 & 2 & 2 & 4 & 2.533333 \\
\hline 18 & Pre & 4 & 5 & 5 & 5 & 4 & 5 & 5 & 5 & 4 & 4 & 4 & 4 & 4 & 5 & 5 & 4.533333 \\
\hline 19 & Pre & 4 & 4 & 3 & 5 & 5 & 5 & 5 & 5 & 3 & 4 & 4 & 4 & 5 & 5 & 1 & 4.133333 \\
\hline 20 & Pre & 1 & 4 & 1 & 1 & 1 & 1 & 5 & 1 & 1 & 1 & 1 & 1 & 1 & 1 & 4 & 1.666667 \\
\hline 21 & Pre & 2 & 4 & 4 & 3 & 3 & 2 & 4 & 3 & 4 & 3 & 3 & 3 & 3 & 3 & 3 & 3.133333 \\
\hline 22 & Pre & 2 & 4 & 4 & 2 & 2 & 2 & 5 & 2 & 1 & 1 & 1 & 1 & 1 & 1 & 4 & 2.2 \\
\hline 23 & Pre & 4 & 4 & 4 & 4 & 4 & 4 & 4 & 4 & 4 & 4 & 4 & 4 & 4 & 4 & 4 & 4 \\
\hline 24 & Pre & 1 & 5 & 4 & 2 & 1 & 1 & 5 & 1 & 2 & 1 & 1 & 2 & 3 & 3 & 5 & 2.466667 \\
\hline 25 & Pre & 5 & 5 & 5 & 5 & 5 & 4 & 5 & 4 & 3 & 3 & 3 & 3 & 4 & 4 & 5 & 4.2 \\
\hline
\end{tabular}




\begin{tabular}{|c|c|c|c|c|c|c|c|c|c|c|c|c|c|c|c|c|c|}
\hline 26 & Pre & 5 & 5 & 5 & 5 & 5 & 3 & 5 & 5 & 3 & 3 & 3 & 4 & 5 & 5 & 5 & 4.4 \\
\hline 27 & Pre & 5 & 4 & 4 & 3 & 4 & 3 & 1 & 4 & 1 & 1 & 4 & 1 & 3 & 4 & 1 & 2.866667 \\
\hline 28 & Pre & 4 & 5 & 5 & 4 & 5 & 4 & 5 & 5 & 4 & 4 & 4 & 2 & 4 & 4 & 4 & 4.2 \\
\hline 29 & Pre & 2 & 3 & 1 & 2 & 3 & 2 & 4 & 3 & 2 & 3 & 3 & 2 & 3 & 3 & 3 & 2.6 \\
\hline 30 & Pre & 3 & 5 & 5 & 3 & 4 & 2 & 5 & 3 & 1 & 3 & 2 & 1 & 5 & 5 & 5 & 3.466667 \\
\hline 31 & Pre & 4 & 5 & 5 & 5 & 3 & 1 & 5 & 2 & 3 & 3 & 2 & 4 & 4 & 4 & 4 & 3.6 \\
\hline 32 & Pre & 3 & 4 & 2 & 2 & 3 & 3 & 5 & 3 & 3 & 3 & 3 & 3 & 4 & 4 & 4 & 3.266667 \\
\hline 33 & Pre & 5 & 4 & 4 & 5 & 3 & 4 & 5 & 4 & 5 & 5 & 4 & 4 & 5 & 5 & 4 & 4.4 \\
\hline 34 & Pre & 4 & 5 & 2 & 4 & 4 & 4 & 5 & 4 & 4 & 4 & 4 & 4 & 4 & 4 & 3 & 3.933333 \\
\hline 35 & Pre & 5 & 5 & 3 & 5 & 5 & 5 & 5 & 5 & 3 & 5 & 5 & 5 & 5 & 5 & 5 & 4.733333 \\
\hline 36 & Pre & 1 & 5 & 5 & 2 & 1 & 2 & 5 & 2 & 2 & 2 & 1 & 3 & 5 & 5 & 4 & 3 \\
\hline 37 & Pre & 2 & 5 & 5 & 2 & 2 & 1 & 5 & 2 & 3 & 3 & 1 & 1 & 5 & 1 & 4 & 2.8 \\
\hline 38 & Pre & 5 & 5 & 3 & 5 & 5 & 5 & 5 & 5 & 3 & 3 & 5 & 5 & 5 & 5 & 5 & 4.6 \\
\hline 39 & Pre & 2 & 4 & 4 & 3 & 3 & 2 & 5 & 2 & 3 & 3 & 3 & 3 & 4 & 4 & 4 & 3.266667 \\
\hline 40 & Pre & 3 & 5 & 5 & 2 & 2 & 2 & 5 & 2 & 3 & 3 & 3 & 3 & 4 & 4 & 5 & 3.4 \\
\hline 41 & Pre & 1 & 4 & 4 & 3 & 2 & 2 & 4 & 3 & 4 & 4 & 3 & 3 & 4 & 5 & 4 & 3.333333 \\
\hline 42 & Pre & 2 & 5 & 2 & 2 & 4 & 4 & 4 & 3 & 3 & 2 & 3 & 4 & 4 & 4 & 4 & 3.333333 \\
\hline 43 & Pre & 2 & 4 & 5 & 4 & 4 & 2 & 4 & 3 & 1 & 1 & 2 & 2 & 5 & 5 & 4 & 3.2 \\
\hline 44 & Pre & 1 & 3 & 4 & 1 & 1 & 1 & 5 & 1 & 3 & 3 & 1 & 1 & 3 & 3 & 4 & 2.333333 \\
\hline 45 & Pre & 4 & 4 & 5 & 5 & 4 & 5 & 5 & 5 & 5 & 5 & 5 & 5 & 5 & 5 & 4 & 4.733333 \\
\hline 46 & Pre & 4 & 5 & 5 & 5 & 5 & 5 & 5 & 5 & 5 & 4 & 5 & 5 & 5 & 5 & 3 & 4.733333 \\
\hline 47 & Pre & 2 & 5 & 5 & 2 & 2 & 1 & 5 & 2 & 1 & 1 & 1 & 2 & 3 & 4 & 4 & 2.666667 \\
\hline 48 & Post & 4 & 4 & 4 & 4 & 3 & 2 & 5 & 3 & 1 & 1 & 1 & 1 & 3 & 3 & 2 & 2.733333 \\
\hline 49 & Post & 3 & 3 & 3 & 3 & 3 & 3 & 3 & 3 & 3 & 3 & 3 & 3 & 3 & 3 & 3 & 3 \\
\hline 50 & Post & 4 & 5 & 3 & 5 & 5 & 3 & 5 & 3 & 3 & 3 & 3 & 3 & 3 & 4 & 2 & 3.6 \\
\hline 51 & Post & 4 & 4 & 4 & 4 & 4 & 4 & 4 & 4 & 4 & 4 & 4 & 4 & 3 & 4 & 4 & 3.933333 \\
\hline 52 & Post & 5 & 5 & 5 & 5 & 5 & 4 & 5 & 5 & 4 & 5 & 5 & 5 & 5 & 5 & 3 & 4.733333 \\
\hline 53 & Post & 4 & 5 & 5 & 5 & 5 & 4 & 5 & 5 & 2 & 2 & 2 & 2 & 5 & 5 & 4 & 4 \\
\hline 54 & Post & 4 & 5 & 5 & 5 & 5 & 5 & 5 & 5 & 5 & 5 & 5 & 5 & 5 & 5 & 5 & 4.933333 \\
\hline 55 & Post & 5 & 5 & 5 & 1 & 1 & 1 & 5 & 1 & 1 & 1 & 1 & 1 & 1 & 2 & 4 & 2.333333 \\
\hline 56 & Post & 4 & 4 & 2 & 3 & 4 & 3 & 4 & 4 & 2 & 4 & 3 & 2 & 4 & 4 & 4 & 3.4 \\
\hline
\end{tabular}

